\title{
CLOUD AND WEATHER SYMBOLS IN THE HISTORIC LANGUAGE OF WEATHER MAP PLOTTERS
}

Robert A. Houze JR. ANd Rebecca Houze

The traditional cloud and weather symbols used in weather mapping have a history deeply rooted in developments in art, science, technology, and international communication.

$H$ ave you ever wondered about the symbols on the AMS ties, scarves, and umbrellas (Fig. 1)? These little designs, somewhat reminiscent of cattle brands, may now seem enigmatic. But during the first 50-75 years of the twentieth century they were important as a shorthand way of indicating the state of the weather and sky seen by an observer at a weather station. Before today's communication technology and automation, skilled technicians plotted observations on weather maps by hand. The staffs of working weather stations in the early to mid-twentieth century included plotters, and these hardworking people were an important part of meteorological practice. During those years, meteorology was distinctly layered into four fundamental functions: 1) Observers would read instruments measuring temperature, pressure, humidity, and wind. In addition, they would note down qualitative information, namely, the weather phenomena occurring at the station and the state of the sky overhead. They would code this information and send it out over telegraph or Teletype so that every weather station would know the conditions at every other weather station over some large portion of Earth. 2) Plotters at a station, or sometimes at a central location, would receive the coded observations, decode them, and plot every station's observations on a

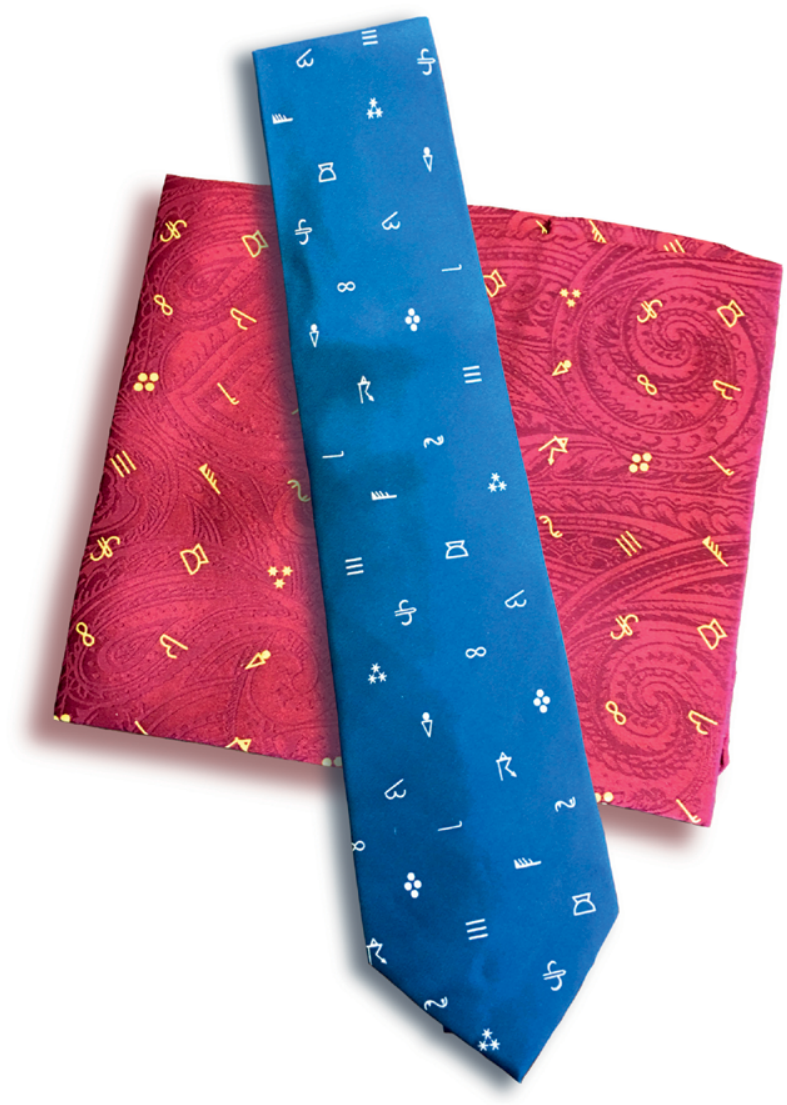

FIG. I. Tie and scarf available from the American Meteorological Society merchandise catalog. 
map. The plotters used the symbols seen on the AMS ties, scarves, and umbrellas to represent the weather and clouds, which were observed not by instruments but by eye. 3) Analysts took the maps provided by the plotters and added analyses in the form of isolines, fronts, highs and lows, which interpolated the plotted data to provide patterns of weather over a large area in which the stations were located. 4) Forecasters used the sequence of analyzed maps provided by the analysts as the basis for prognostication that served aeronautical and seagoing navigation, agriculture, military operations, severe weather warning, and other applications.

Our paper remembers and celebrates the plotters, whose work laid the foundation for weather analysts and forecasters. The fully analyzed weather map, based on plotted station observations, was the fundamental element of progress in meteorology as a science. Strategies for producing and disseminating analyzed maps of atmospheric conditions over broad expanses of the globe have been the subject of several historical works. Monmonier (1988, 1999), Fleming (1990, 2016), Anderson (2006), and Edwards (2010) detail how international organization and coordination of government weather services have been essential to developing common practices of representing simultaneous atmospheric conditions over broad regions. Anderson's work, in particular, chronicles the experimentation with different methods of mapping that have led to today's common practices for mapping weather over large areas. These historical studies focus on the messages contained in fully analyzed weather maps, with their isolines, fronts, and other features that allow the user of weather information to grasp global or regional weather patterns at a glance.

Somewhat overlooked in these studies has been the role of the workers and methodologies that underpinned the ability to map atmospheric phenomena over vast regions. The observers, who recorded

AFFILIATIONS: R. A. HouzE-University of Washington, Seattle, Washington; R. HouzE-Northern Illinois University, DeKalb, Illinois CORRESPONDING AUTHOR: Robert A. Houze Jr., houze@uw.edu

The abstract for this article can be found in this issue, following the table of contents.

DOI:10.II75/BAMS-D-19-007I.I

A supplement to this article is available online (I0.II75/BAMS-D-19-007I.2)

In final form 20 August 2019

(C)2019 American Meteorological Society

For information regarding reuse of this content and general copyright

information, consult the AMS Copyright Policy. instrument readings and visually evaluated the state of the sky and weather at a station, were, of course, critical. But in this paper we highlight the role of the map plotters, who entered the observational information at the location of each weather station onto blank maps. This plotting was a critical step in making it possible for analysts to interpret and extrapolate the information in a way that created maps showing broad patterns of atmospheric circulation that were consistent with the data plotted at each station.

The weather map plotter had to work under pressure, with skill and efficiency. A plotter had to create a new current weather map every time a new set of observations from stations around the world arrived over telegraph or Teletype. The information arrived in an alphanumeric code, and the plotter would have to decode and write the information on a map at the location of each station. The information had to be entered quickly in order for the plotted map to be current, it had to be entered at each station in a universally accepted format, and it had to be legible so that the analyst could take over the plotted map and quickly prepare the analyzed map. ${ }^{1}$

The legions of weather map plotters at work in the early to late 1900s, who skillfully performed this crucial function, are now extinct, as technology has replaced the need for their unique handicraft. So in this centennial year of the AMS, it seems appropriate not to forget these bygone but important and unsung contributors to meteorology. To remember them, we focus on the symbols they used to represent the descriptive observations of clouds and weather. The plotters of course had to inscribe the numerical information on wind, temperature, humidity, and pressure at each station. But the descriptive information from visual observations of sky and weather at each site could not be entered numerically. Instead, ingeniously simple symbols suggestive of the visual observations were quickly drawn at each point on

\footnotetext{
${ }^{1}$ Long before winning the Rossby Medal of the American Meteorological Society and the Symons Medal of the Royal Meteorological Society, author RAH's first job in meteorology was as a map plotter at Texas A\&M University, where he plotted the maps for classes in synoptic meteorology in the 1960s. In the 1970s after RAH became a Professor in the Department of Atmospheric Sciences at the University of Washington, coauthor RH, herself now a Professor of Art History at Northern Illinois University, remembers as a child watching Lorrie Grider plotting maps from Teletype reports for the department's synoptic meteorology classes. Lorrie was an expert plotter, who had learned the skill while she was serving in the U.S. Navy.
} 
the map where visual observations were made. The symbols on the AMS merchandise were among those used to quickly plot all the data from every station on a map of the United States or some other region of the globe. These quickly drawn symbols for clouds and weather phenomena seen by an observer facilitated the necessarily fast plotting and efficient nonverbal representation of complex descriptive information about the weather at a given location.

From about the mid-1940s to the end of the 1960s, handcrafted weather mapping using these symbols reached a pinnacle of skill and expertise. Subsequently, the communication of images by facsimile allowed maps to be created in a central location and disseminated to weather stations in fully finished form, eliminating the need for an army of skilled plotters distributed around the world. By the 1990s, facsimile transmission was being replaced by the transmission of imagery over the internet. Increasingly sophisticated computer-generated forecast products began replacing the need for traditional weather maps, and local forecasters evolved into interpreters of maps of centrally generated numerical model output.

In this centennial year of the AMS, we revisit this period of historical interest, with the theme of cloud and weather symbols used by map plotters, to consider whether anything in terms of representing and thinking about weather has been lost in the digital technological age to which we are now bound. The traditional surface weather map, which reached its highest form as a manual craft during the mid-twentieth century, started with the hand plotting of observational data at each reporting station's location on a map. The symbols representing the observers' description of the clouds and weather occurring at every station on the map were an important part of this manual plotting skill. The design of these small ideographs used in hand plotting to represent cloud and weather elements has a surprisingly rich history. Clouds and weather, of course, have been the subject of both artists and scientists for centuries. Weather on the ground and clouds in the sky are essential to people's experience of Earth's atmosphere. While numerical quantities like rain amount and cloud-base height can be measured in numbers and serve as input and output variables for numerical forecasts, they do not tell the whole human story of what is happening weatherwise at a specific time and location. What it looks like out the window is as much feeling as fact. The cloud and weather observations represented on a map therefore tell what conditions looked and felt like in ways that relate to people's experience, which explains why the cloud and weather symbols on the AMS souvenirs are so important, appropriate, and endearing. We suggest that as hand plotting of observations of clouds and weather at individual stations has become more automated and numerical, this human experiential element of the weather map has been lost. So, as part of the retrospective look at

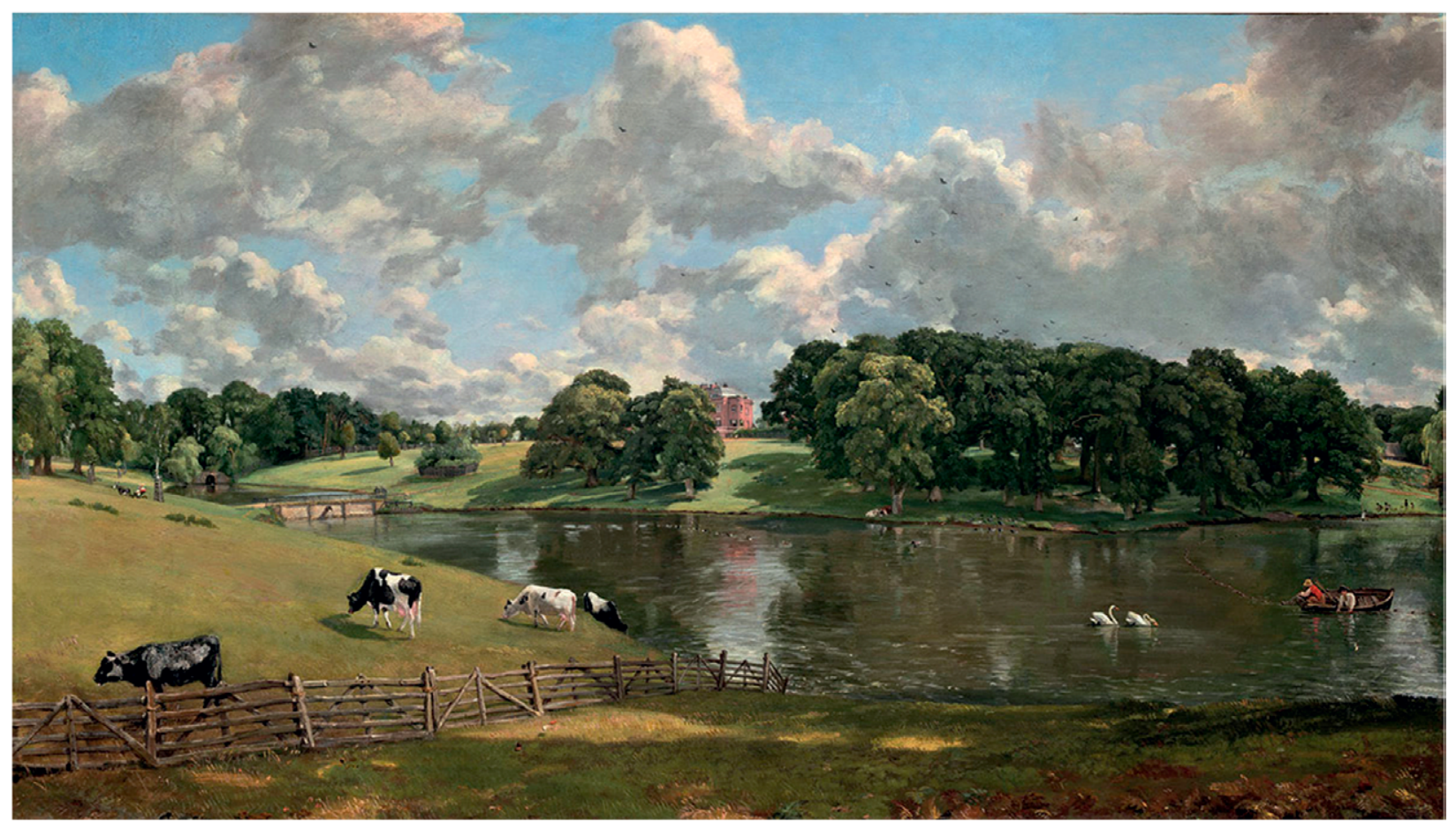

Fig. 2. John Constable. Wivenhoe Park, Essex. 1816. Oil on canvas. National Gallery, Washington, D.C. 
meteorology in the centennial year of the AMS, we examine here how meteorologists represented weather phenomena and clouds symbolically at the pinnacle of the era of weather mapping by the human hand, how the symbols used in this activity formed and evolved over time, ways in which this representation of the human experience of clouds and weather might be vanishing in today's technological age, and why this loss might have consequences.

\section{CLOUD SYMBOLS: REPRESENTATION OF AESTHETIC BEAUTY AND MEANINGFUL SCIENCE IN SIMPLE STROKES OF A PEN.}

People have long been fascinated and inspired by clouds. In the early 1800s, British landscape painters John Constable (1776-1837) and William Turner (1775-1851) were well known for their naturalistic representations of atmospheric phenomena. Constable's painting Wivenhoe Park (Fig. 2) depicts cumulus clouds over English farmland with attention to visual accuracy based on his own observations. The pastoral foreground with the rustic fence suggests how the clouds form part of the scene of everyday life. Contemporary discussions of these works emphasize the experiential aspect of atmospheric conditions. For example, the outspoken and influential modern art critic of the time John Ruskin (1819-1900) propounded a preference for Turner's dramatic renderings

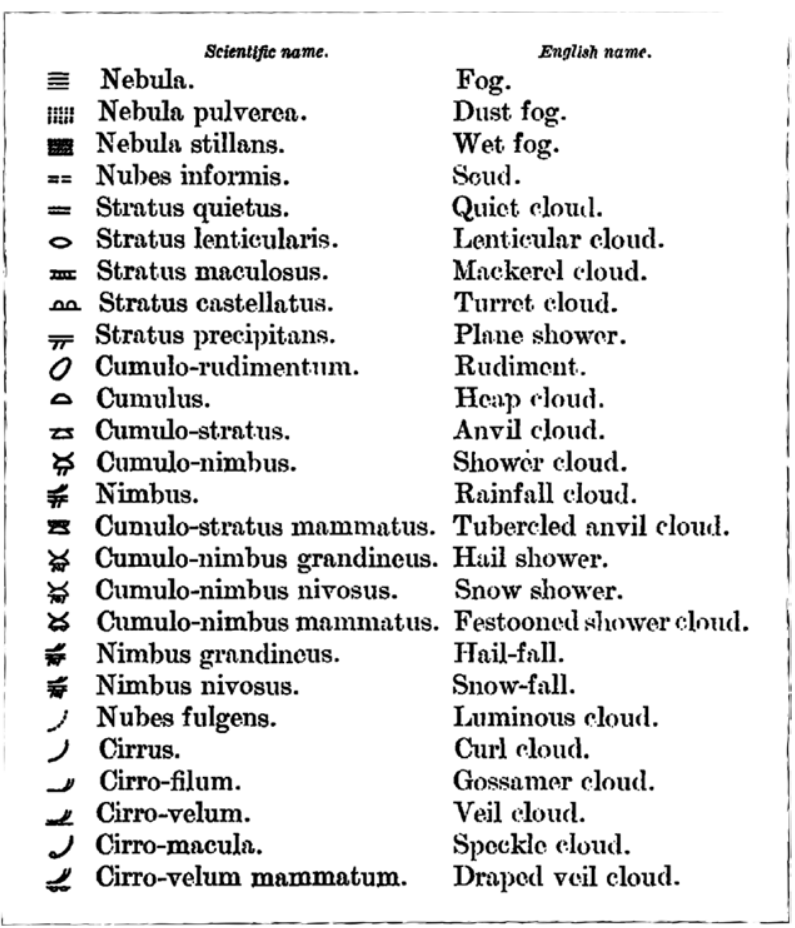

FIG. 4. Cloud symbols suggested by Ley (1894) in his book Cloudland, here shown as reproduced in Talman (1916).

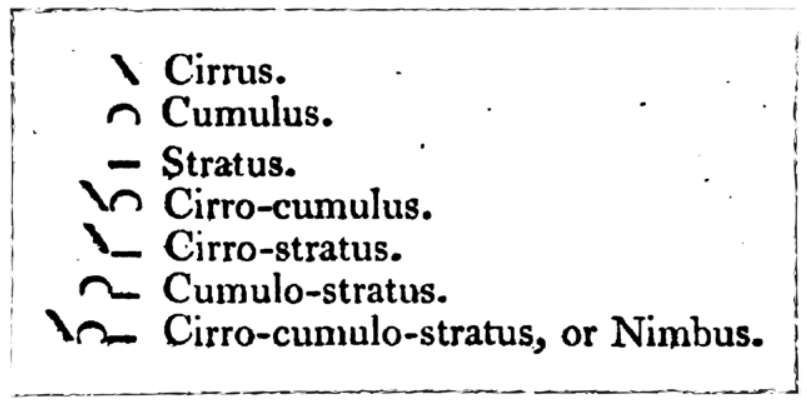

Fig. 3. Cloud symbols suggested by Howard (1803, p. 345).

of violent Alpine thunderstorms and fiery sunsets above the Thames to Constable's careful depictions of the tidy English countryside in pleasant weather (Rees 1982).

The first half of the nineteenth century was a time when the intellectual worlds of art and science were coming together, and it was actually the London Meteorological Society's Transactions that published one of Ruskin's early articles about nature observation (Ruskin 1839). Long before airplanes and satellites, clouds dominated the human perception of the sky and were thus at the center of the early nineteenth century's convergence of art and science. Poetry as well as visual art was part of this movement, exemplified by Johann Wolfgang von Goethe's (1749-1832) poem "In Honor of Howard." This poem muses about how human imaginations roam free when looking at clouds in the sky:

Here lions threat, there elephants will range,

And camel-necks to vapoury dragons change.

Goethe's title refers to the English pharmacist and amateur meteorologist Luke Howard (1772-1864), who in 1803 suggested a set of evocative symbols to signify the three fundamental cloud forms by the simplest of line drawings: a diagonal line for cirrus, a semicircular curve for cumulus, and a horizontal bar for stratus (Fig. 3). These simple, quickly executed strokes of a pen convey in an efficient way the complexities that Turner and Constable painted and that Goethe sought to describe in words.

Later in the nineteenth century, in the scientific world, three other key figures emerged in an effort to identify the different types of clouds seen from the ground and decks of ships. These were the Scottish meteorologist Ralph Abercromby (1842-97), the Swedish physicist Hugo Hildebrand Hildebrandsson (1838-1925), and the English clergyman and early meteorologist William Clement Ley (1840-96). 
All three realized the importance of connecting pictures of clouds with their naming and their symbolic representation. Abercromby (1887) wrote of "the impossibility of expressing the varying forms of clouds in words." It was becoming obvious that clouds took so many fundamentally different forms that Howard's three symbols were insufficient on their own for observers to characterize the state of the sky. In an 1894 treatise called Cloudland, using a combination of artwork and a few early photographs, Ley (1894) elaborated on Howard's three basic cloud-form symbols to

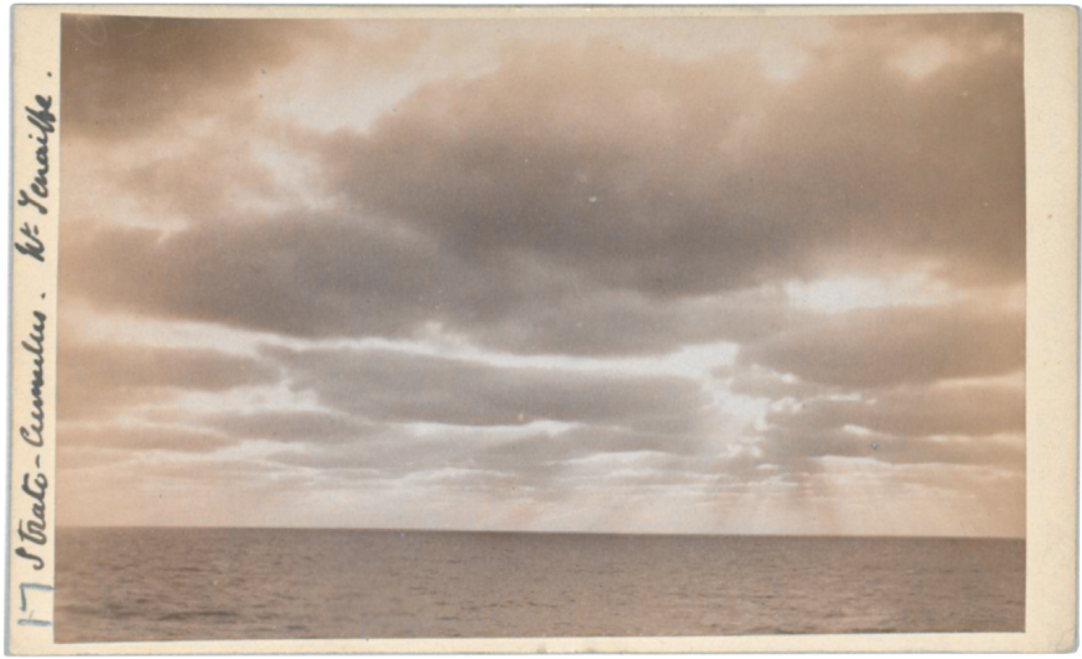

Fig. 5. An example from Ralph Abercromby's collection of photos that he took on his around-the-world tour documenting clouds at diverse locations. This example taken at Tenerife in the Canary Islands shows stratocumulus clouds over the subtropical ocean. Courtesy Met Office Library Archives.

suggest symbols for a large

number of variations and hybrid symbols (Fig. 4). One combination of these shapes, for example, was the use of small concave downward curved lines atop a horizontal bar, to represent stratus castellatus (or what we now call altocumulus castellanus). Three quick strokes of the pen evoked the unmistakable form of a turreted medieval castle or city wall. For both Howard and Ley, imaginative, visually evocative but simple-to-execute cloud symbols lent themselves not only to efficient notation of the condition of the

skies, but more significantly, to a rich, physically meaningful, and nuanced visual depiction of the varying sky on expansive weather maps that covered vast geographical territory, extending the reach of what could be observed by a single set of eyes in one location at a given moment.

In the late nineteenth century, photography was still in its infancy, but Ley, Abercromby, and Hildebrandsson saw its potential power and became advocates of using photographs of clouds to relate to nomenclature and symbols.

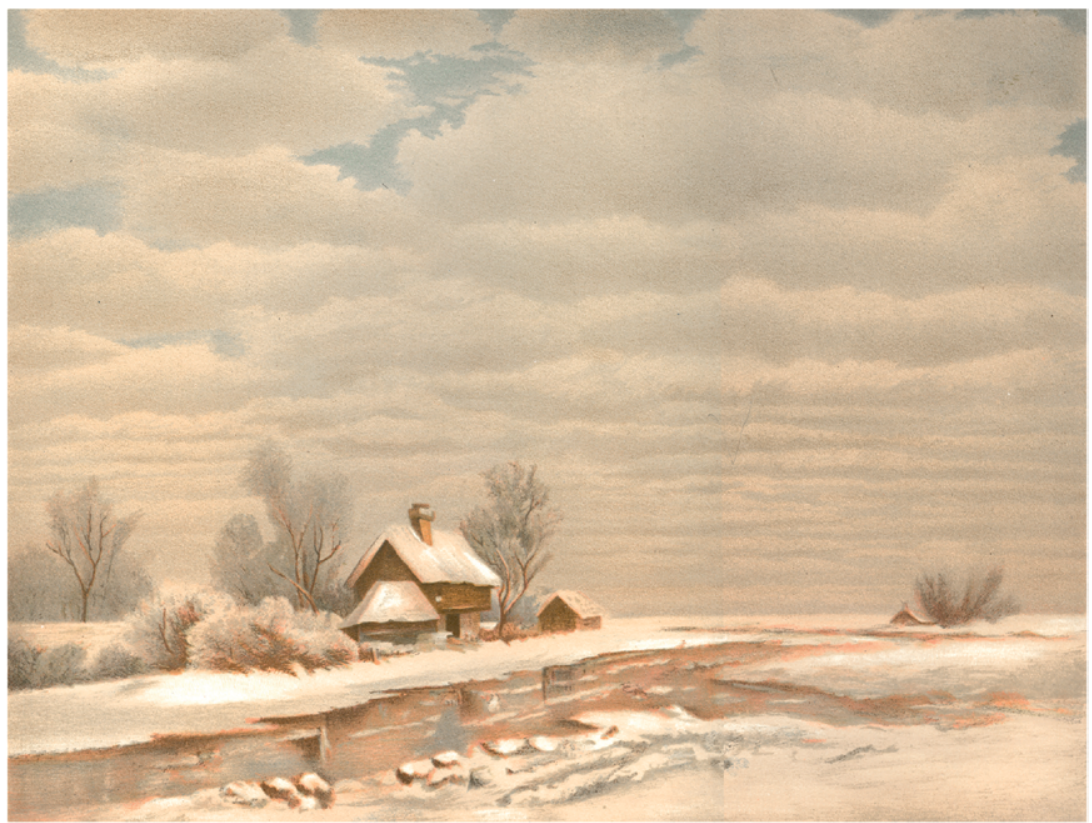

Fig. 6. Illustration of stratocumulus cloud in the cloud atlas of Hildebrandsson et al. (1890, plate 6).
Photography could capture the transient and ephemeral nature of clouds much more efficiently than the slow processes of sketching and painting. But in these early days of photography it was nevertheless difficult to capture the fleeting forms of clouds on glass plates. As a result, early cloud atlases had to rely on combinations of photographs with hand-illustrated renderings of clouds to guide nomenclature. After trying unsuccessfully to collect cloud pictures from other people, Abercromby spent a decade traveling around the world taking pictures of clouds, which were printed as miniatures on paper $113 \mathrm{~mm} \times 62 \mathrm{~mm}$, which 
he described as the size of a calling card of the type used by the Victorian-era gentry (Abercromby 1887; Fig. 5). These travels led him to the conclusion that an international system of cloud identification was essential because "cloud forms are the same all over the world"- a fact we now take for granted, but which was not known at that time. In the course of his travels he "had the opportunity of conversing with the Directors of many Meteorological Institutes in various parts of the world, and...found that though some forms of cloud were almost universally assigned the same name, others-especially the lower clouds-received a dif-

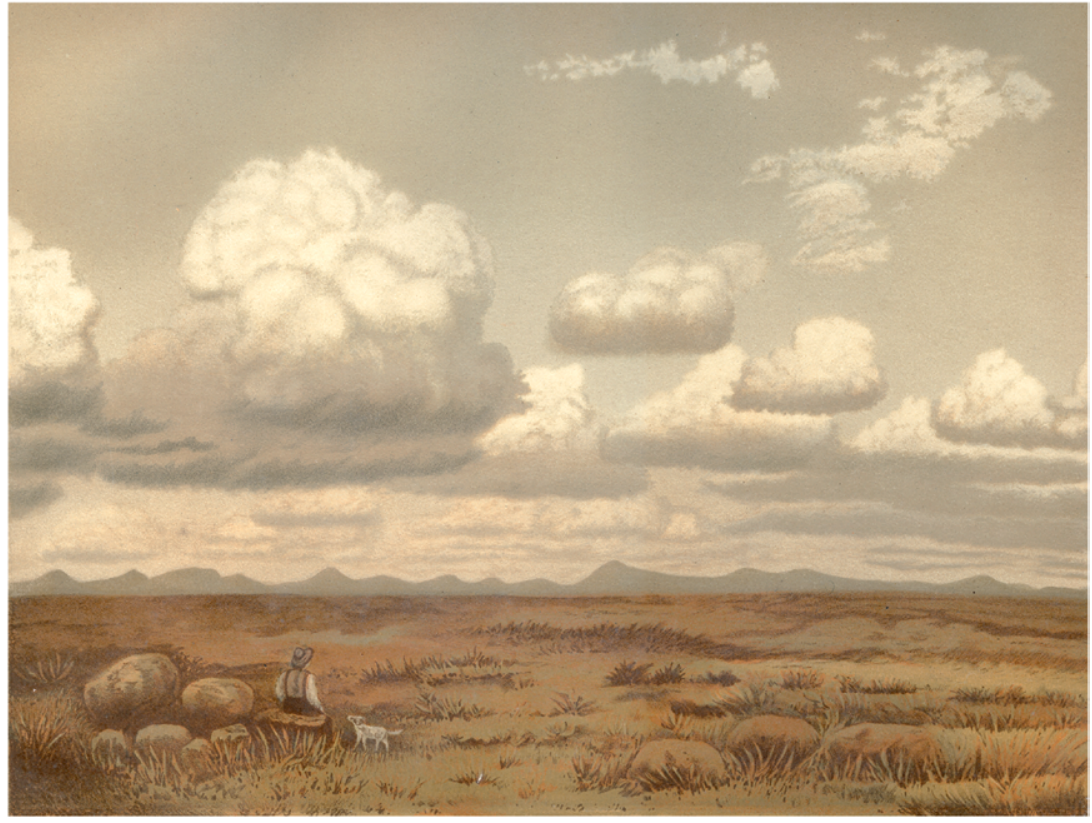

Fig. 7. Illustration of cumulus cloud in the cloud atlas of Hildebrandsson et al. (1890, plate 8). ferent name from nearly every

Director." He declared, "The question of an International Nomenclature of Clouds becomes of the highest importance." Hildebrandsson shared Abercromby's opinion that a naming system for cloud types was sorely needed, and they developed similar ideas for this much-needed taxonomy, although they publicly disagreed about names that should be used (Abercromby 1887; Hildebrandsson 1887). Along with Wladimir Köppen (1846-1940) and Georg Balthazar von Neumayer (1826-1909), Hildebrandsson published

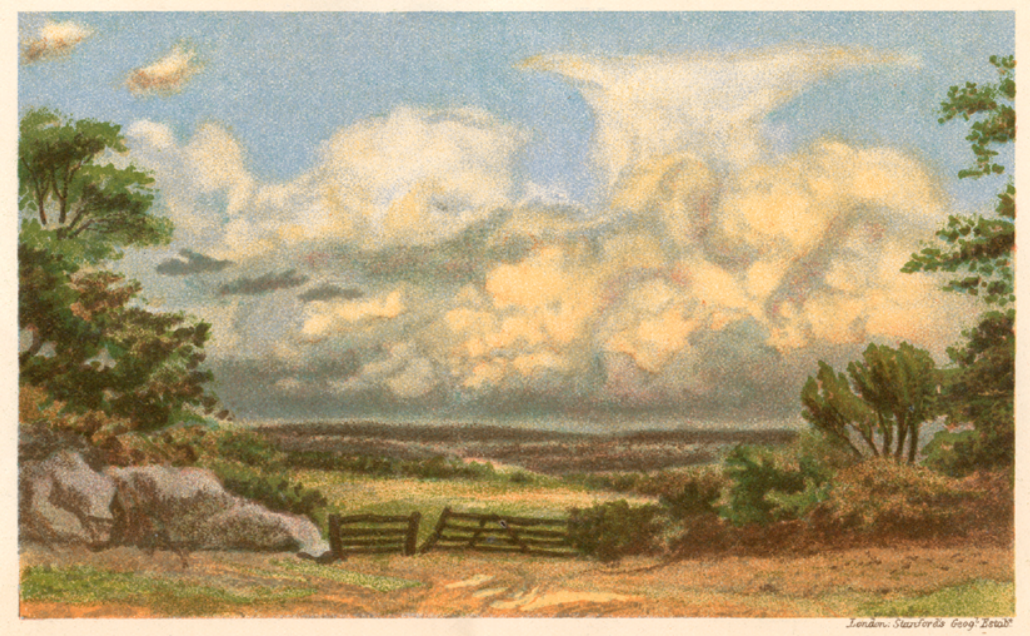

CUMULO - NIMBUS

Fig. 8. Illustration of towering cumulus and cumulonimbus in Cloudland (Ley 1894, frontispiece).
Wolken-Atlas, an early pictorial atlas of cloud types (Hildebrandsson et al. 1890). But at this stage, even with the apparent availability of Abercromby's collection of cloud pictures, the atlas was primarily a portfolio of full-page paintings of each of the basic cloud types with only a few small black and white photos used to supplement the verbal discussion of cloud types. Ley's Cloudland published just four years later (Ley 1894) was not an atlas but rather a verbose monograph attempting to explain cloud formation processes and their relation to larger atmospheric circulations. However, like Wolken-Atlas, it also made heavy use of artwork for its illustrations, supplemented by just a few small black and white photographs, with one of its purposes being to connect cloud pictures with his symbols and naming system (Fig. 4).

The paintings used by Hildebrandsson et al. (1890) and Ley (1894) are interesting not only for the clouds they illustrated but also for the way that the scenes were composed. Like Constable's pastoral painting in Fig. 2, the foregrounds of these paintings emphasize 
how the cloudscapes relate to human experience. For example, Fig. 6 shows a sky of gray stratocumulus hovering over a wintry scene depicting a snow-covered farmhouse. Figure 7 shows a rural man and his dog looking out over a vast scrubland with a sky of flat-based cumulus clouds reaching into the distance to a faraway mountain range. Figure 8 illustrating larger cumulus clouds and cumulonimbus is a clear imitation of Constable's pastoral scene of farmland under the cloudy sky. This illustration was the frontispiece of Cloudland and illustrates with little doubt how profoundly the early cloud atlases were influenced

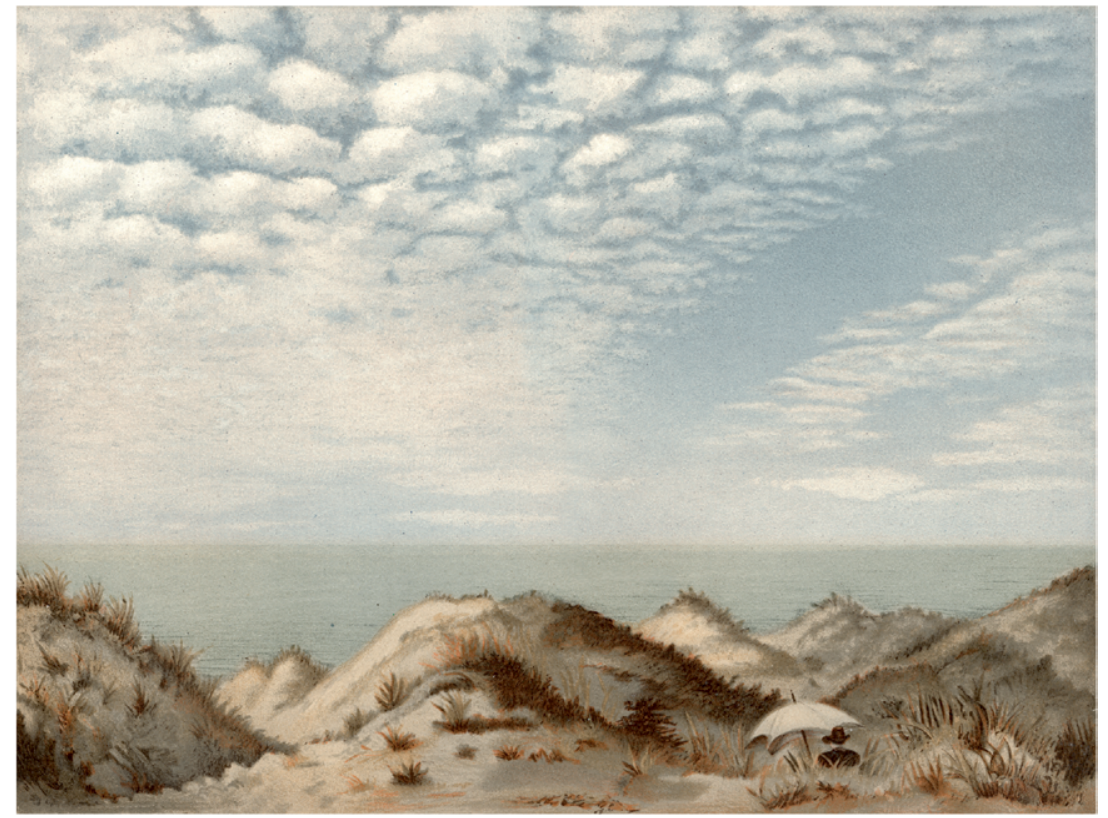

Fig. 9. Illustration of altocumulus cloud in the cloud atlas of Hildebrandsson et al. (1890, plate 4). by the earlier landscape painters. The emphasis on human experience of the skies was clearly an important aspect of the illustrations of cloud types in both the 1890 Wolken-Atlas and 1894 Cloudland.

Altocumulus clouds have been especially inspirational. In Cloudland, Ley says, "Many of the skyscapes due to the occurrence of Stratus Maculosus are of very great beauty. The minute rounded masses, compared by some authors to a flock of sheep lying down, produce in perspective an impression of quiet grandeur, and delicate colouring and elegant mottled appearance, which cannot fail to excite admiration in an artistic mind" (Ley 1894). When the cloud elements are elongated, they evoke a school of fish, expressed colloquially and in literature as "mackerel sky" (e.g., by John Updike in Rabbit Run). This common usage was Latinized by Ley (1894) as Stratus maculosus. The illustrations of altocumulus clouds in the early cloud atlases strongly reflect the human experience of altocumulus skies. Figure 9 shows a person sitting among sand dunes along a shore. A field of altocumulus cloud extends over the water and vanishes in the distance. This painting was perhaps a self-portrait of the artist, who like many people meditating on a beach, was evidently inspired by a scene enhanced by the cloud-filled sky above. Four years later, in Cloudland, Ley (1894) included a somewhat similar painting of altocumulus vanishing in the distance but in this instance over a wide landscape of arid hills (Fig. 10). This type of scene often inspires the human perception of the vastness of Earth's reach in relation to people's experience. Driving across open country, one might be tempted to pull over and photograph a similar scene. If the foregrounds were removed from the paintings in Figs. 9 and 10, the illustrations would not contain the impression of how the scene felt and

Fig. 10. Illustration of altocumulus in Cloudland (Ley 1894, plate III). 
would be uninteresting views of clouds with no experiential perspective. Figure 11 is an early photograph of altocumulus that was also in Cloudland. This photo was embedded as a small illustration in the text of the book used only to supplement the defining Fig. 10.

But technology was rapidly developing, and photographs of clouds were soon to replace hand-illustrated renderings as the reference for cloud nomenclature. In 1896, Hildebrandsson, working with Swiss meteorologist Albert Riggenbach (1854-1921) and French meteorologist Léon Teisserenc de Bort (1845-1918), produced the first mostly photographic International Cloud Atlas (Hildebrandsson et al. 1896).

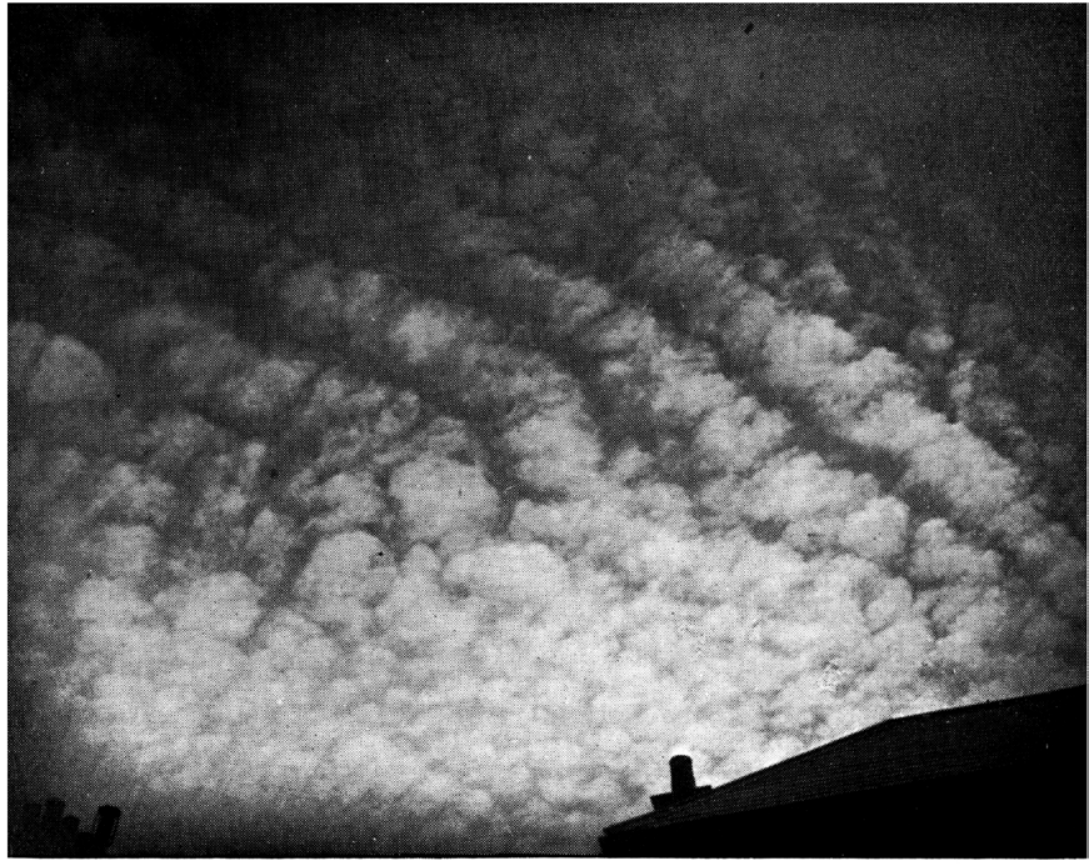

Fig. II. Photograph of altocumulus in Cloudland (Ley 1894, p. 54, illustration I).

This atlas was notable for

its inclusion of a number of chromotypographs of certain types of clouds. Chromotypographs were an innovation in industrial print technology, which enabled publishers to mechanically reproduce black and white photographic images with rich tonal gradation

in colored inks. The name combines "chromo" (color) with "typographic" (the design and arrangement of letterforms for the printed page). These chromotypographs were forerunners of the high-quality color photographs used in today's online International Cloud Atlas. Figure 12 is the

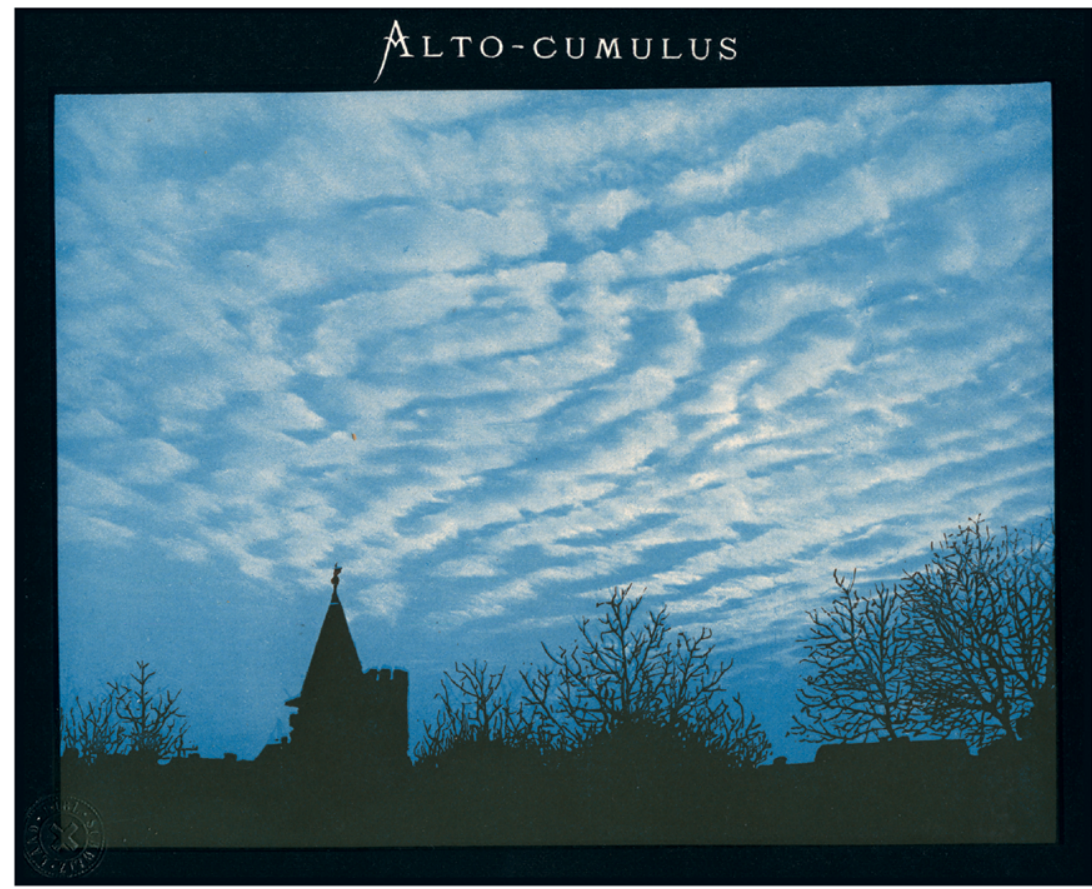

Fig. 12. Chromotypograph illustrating altocumulus in Fig. 10 of the International Cloud Atlas of Hildebrandsson et al. (1896). chromotypograph used by Hildebrandsson et al. (1896) to replace the artists' renderings of Figs. 9 and 10. For comparison, Fig. 13 shows a high-resolution photograph from the current version of the International Cloud Atlas. This modern photo is strikingly similar to the early chromotypograph, not only in detail but also in composition. The foreground silhouette of trees and buildings gives both the chromotypograph and modern photo a human perspective, indicative not only of scale but also suggestive of the mood of the scene. The now frequent posting of digital photographs of clouds on social media underscores the importance of clouds affecting mood but as 
yet the voluminous archive of such photographs has not changed the classification of clouds represented by the symbols on maps.

The creation of pictorial cloud atlases in the 1890 s coincided with a nineteenth-century movement of European and American scientists to standardize meteorological observations so that weather mapping would be understandable and useful in tracking weather events across international borders. The first international conference on these matters was in Brussels in 1853, and among the agreements reached was the matter of codes and symbols for observed clouds (Pouncy 2003). That conference was an ad hoc meeting of scientists concerned about the organization of meteorology. A subsequent conference was held in Vienna in 1873, at the time of the International Exposition, when the necessity for increasing and improving communication among nationalities affected many disciplines, including meteorology. The Vienna conference formalized a consortium of meteorologists from various countries by overseeing the formation of the International

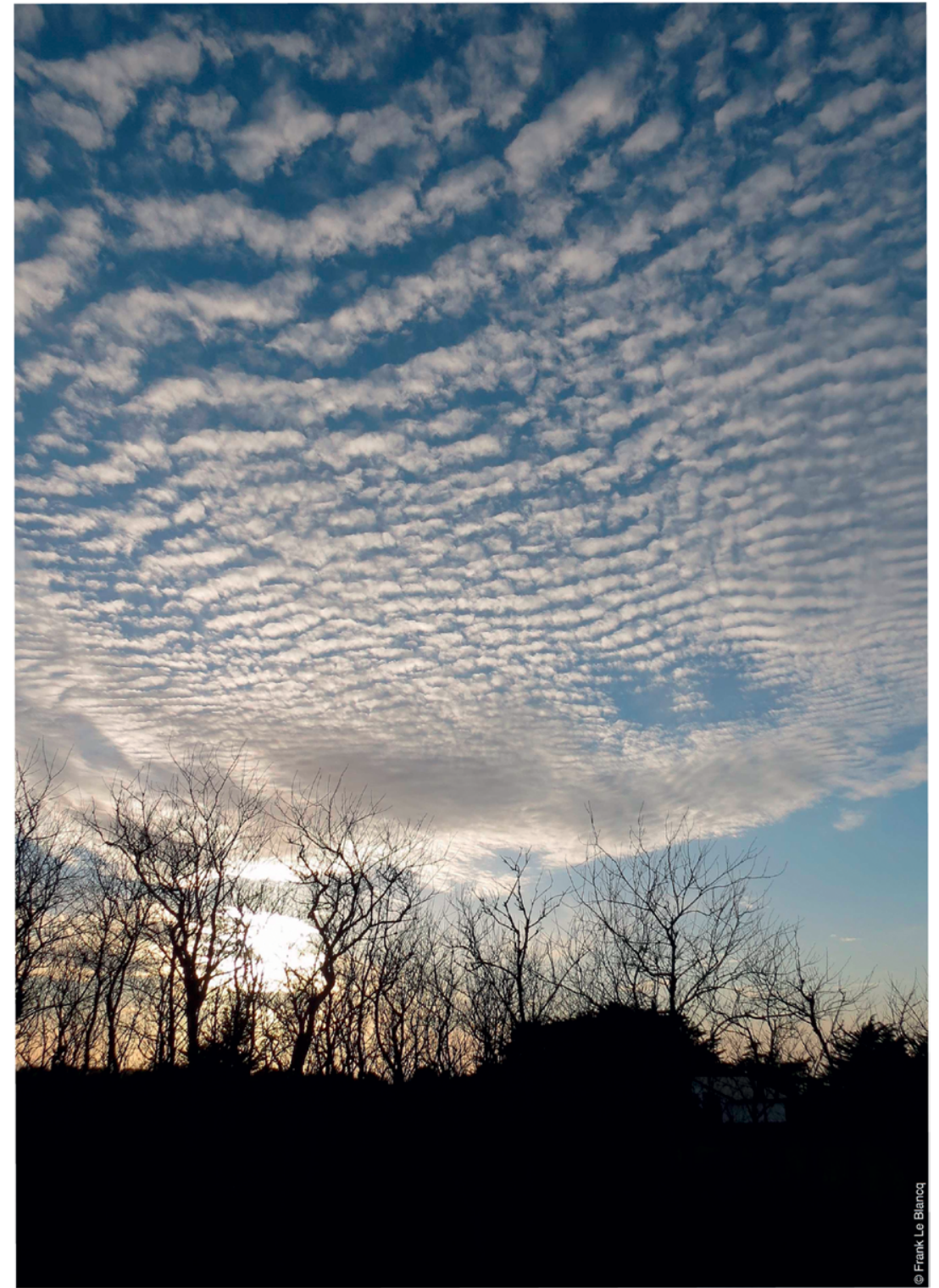

FIG. 13. High-resolution photograph of altocumulus in the 2017 online version of the World Meteorological Organization's International Cloud Atlas. See https://cloudatlas.wmo.int/home.html.
Meteorological Organization

(IMO), the forerunner of the World Meteorological Organization (WMO). The IMO held an especially important follow-up meeting in Munich in 1891. According to the meeting's rapporteur (Scott 1892), a particularly long and disputatious discussion was devoted to the identification of clouds, but when brought to a vote, "The resolution of the Conference, carried by a large majority, was to adopt the classification of clouds, with 10 grades, proposed by Prof. Hildebrandsson and Mr. Ralph Abercromby." A committee was then formed to follow up with the task of forming a cloud atlas "to introduce uniformity in the classification and nomenclature of cloud observations." The 1896 version of the International Cloud Atlas (Hildebrandsson et al. 1896) was the result of that committee's work. This outcome was probably the most important step in establishing the 10 basic cloud types still in use today. In the United States, Cleveland Abbe (1838-1916), a key early promoter of coordinated telegraphy of meteorological observations, adopted these basic cloud types and advocated that station observers systematically record the types present at a given time on a common observational form (Richards and Abbe 1898). The IMO and WMO have revised the atlas many times since 1896, with the use of ever more clear and beautiful 


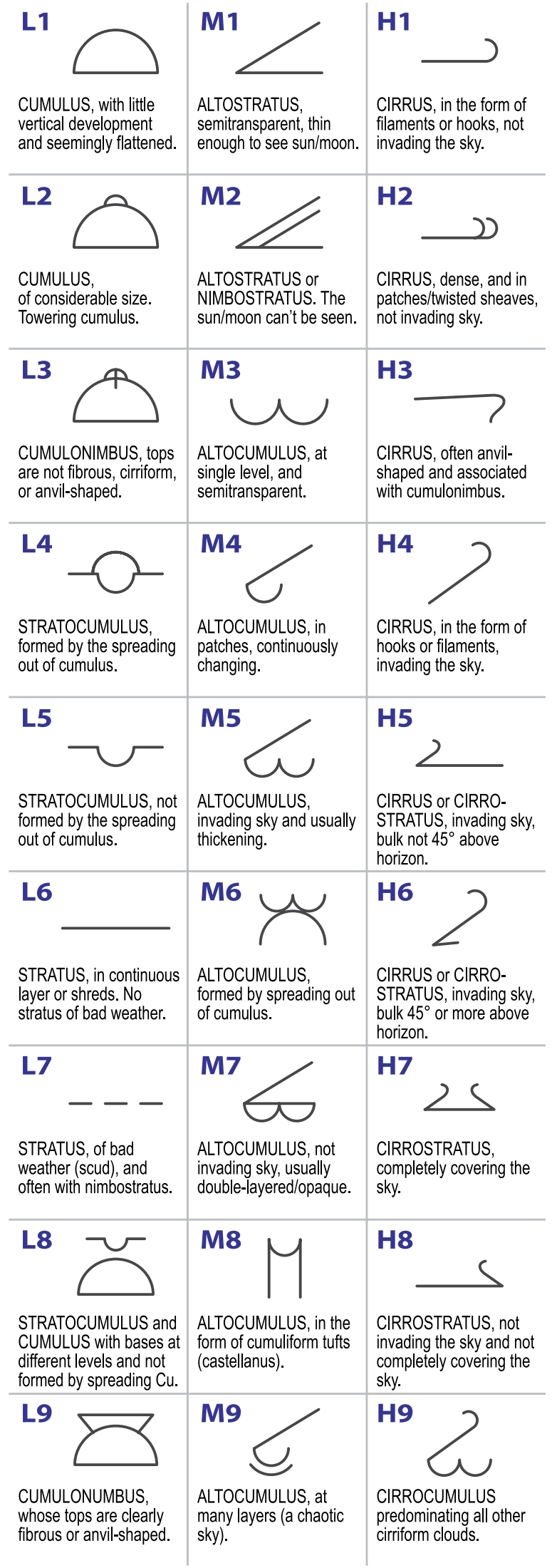

FIG. 14. Cloud symbols, codes, and descriptions used by the World Meteorological Organization (WMO 2017). photography, but always with 10 basic cloud types. The 2017 revision of the WMO's International Cloud Atlas is available online (https://cloudatlas.wmo.int/). Its 10 basic cloud types, indicated by uppercase words in Fig. 14, correspond precisely to the categories identified by Abercromby and Hildebrandsson and listed at the end of Abercromby's (1887) paper, albeit with somewhat different names than are used now. A comparison of the 10 names used by Abercromby and in the modern lexicon is provided by Pouncy (2003).

The 10 basic cloud types identified by Abercromby and Hildebrandsson occur in a variety of structural variations and hybrid forms. Figure 14 therefore integrates the 10 basic types into 27 specific and frequently observed combinations, each to be indicated on maps by a specific symbol. These symbols are clearly descendants of those of Howard and Ley (Figs. 3 and 4). The 27 varieties are subdivided into three groups of 9 specific cloud types considered to be low, middle, or high, where the heights are those of the bases of the clouds. These categories have been institutionalized, standardized, and illustrated by the International Cloud Atlas and the WMO "Manual of codes" (WMO 2017) with little modification since the early 1900s. As Abercromby and Hildebrandsson hoped, these identifiable cloud types have succeeded in making the language of cloud identification efficient. The nineteenth-century meteorologists thus produced a stable and enduring legacy allowing the complexities of cloud variations to be embodied neatly in a family of simple definitions and graphic symbols readily applicable for use on maps. The 27 basic cloud types in Fig. 14 have appeared unchanged for about a century, not only in the WMO's current International Cloud Atlas but also, significantly, in the WMO "Manual of codes" (WMO 2017), which indicates that the symbols in Fig. 14 should be used on maps to indicate cloud types seen by weather observers on Earth's surface.

A frequent point of confusion after the launch of the first weather satellites is that the WMO categories of low, middle, and high clouds in Fig. 14 refer to the height of cloud base, not cloud top. Cloud types like cumulonimbus and nimbostratus may reach great heights but remain classified as low, according to the height of cloud base. Satellite-based nomenclature often uses cloud-top height to distinguish cloud types (e.g., Rossow and Schiffer 1999), and that lexicon is useful for many scientific studies. But for surface weather reports, which convey the experience of a person on the ground, or of a ship, or the needs of a pilot of an aircraft landing or taking off, the more relevant height is cloud base. For these reasons, the "Manual of codes" retains the categories 
by cloud-base height for surface weather reporting and mapping.

One of the reasons that the cloud types and corresponding symbols in Fig. 14 have had a stable and successful history is that they do not require the observer to make a determination of the atmospheric physical and dynamical processes producing the visible cloud forms. An observer need only be trained to recognize shapes; it is not the observer's responsibility to interpret how the clouds are being formed. And yet these astutely distinguished types, based solely on appearance, have turned out to have crucially distinct physical interpretation. Books on the physics and dynamics of clouds have been organized around these types (e.g., Houze 2014). Their use in plotting weather observations on maps thus adds physical meaning to the report of weather conditions at a particular location on a map as well as a subjective representation of how the state of the sky seemed to a person on Earth's surface. The fact that these basic cloud categories and symbols are both easily applicable and carry physical meaning is a testament to the cleverness of the nineteenth-century advocates of cloud study.

WEATHER SYMBOLS: A GRAPHIC SYSTEM RELATED TO WRITING. Besides the state of the sky overhead, reports from meteorological stations include other information about the experience of atmospheric conditions on the ground or on the deck of a ship at sea. Like clouds, these conditions cannot always be simply expressed as numbers. The conditions at Earth's surface, as opposed to the sky overhead, are what meteorologists classify as "weather." These conditions include rain, snow, hail, drizzle, fog, sleet, lightning, haze, smoke, blowing dust, snow, and several variants of these phenomena. They represent the diverse ways that the atmosphere affects us as we go about the business of our daily lives. Meteorologists have been thinking about how to represent these conditions on a map for more than two centuries, and the symbols we use today, like the symbols for clouds overhead, have undergone an evolution. Interestingly, while cloud iconography was influenced by visual art, weather symbols have had a rather different history, seeming influenced more by technology than art. In contrast to the cloud symbols, which took the form of abstract shapes reminiscent of naturalistic yet complex cloud forms, the weather symbols have been built largely on the nonalphabetic elements of writing, such as punctuation marks, which became increasingly standardized in the development of different typefaces used for printing.

Weather symbols suggested

by Lambert in 1771

Cloud

Rain

Snow

Fog

Thunder
Fig. 15. Rudimentary symbols proposed for basic weather elements by Lambert (177I, p.63).

Much like today's keyboard-created emoticons popularized in the early computer age, weather symbols make extensive use of commas, periods, hyphens, apostrophes, brackets, asterisks, and tildes. Three decades before Luke Howard introduced the elemental cloud symbols, the Swiss scientist Johann Heinrich Lambert (1728-77) suggested the basic elements of weather symbols (Fig. 15). They comprised simple lines, apostrophes, $\mathrm{x}$ marks, dots, and a zigzag form attempting to represent clouds, rain, snow, fog, and thunder. These minimalist marks recalled complex phenomena and were the seeds from which modern symbols have evolved. The $\mathrm{x}$ marks representing snow and the zigzag representing thunder (often associated with a lightning stroke) are clear progenitors of the modern symbols in which an asterisk is used for snow and various zigzags are used for different forms of thunder and lightning. These elements are pictorially suggestive, with the branches of the $\mathrm{x}$ or asterisk suggesting a snowflake and the dot or period suggesting rain, yet they are largely derived from abstract systems of writing, except for the bent arrow for thunder. Through subsequent years, up until present times, the dominant features of the weather symbols have remained largely the same. In their shorthand notation, they expressed not only the practice of handwriting, but also the new technologies of writing and printing in a world increasingly defined by industrial mechanical reproduction and the quick transmission of information. 


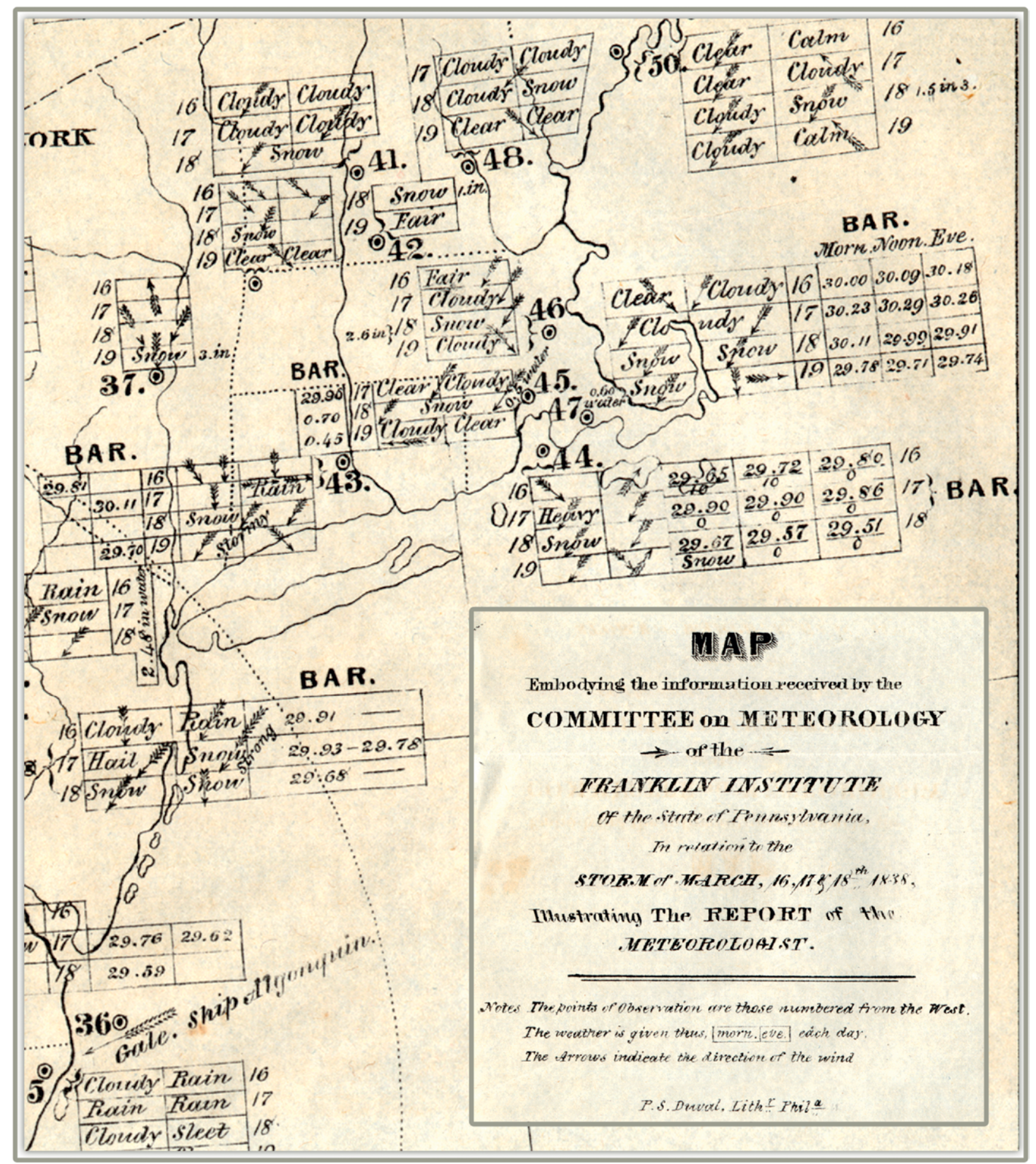

FIG. 16. Weather map printed by the Franklin Institute "embodying the Information Received by the Committee on Meteorology of the Franklin Institute of the State of Pennsylvania in Relation to the Storm of 16th, 17th, \& 18th, Mar 1838." From Espy (1838) and viewable online (http://libweb5.princeton.edu/visual_materials/maps /websites/thematic-maps/quantitative/meteorology/meteorology.html).

Lambert was somewhat ahead of his time. Weather mapping and forecasting did not take on rapid development until the nineteenth century; particularly following the introduction of the telegraph. Electrical communication enabled simultaneous transmission of data by wire from many points on Earth, and interest in producing current synoptic maps showing simultaneously the weather conditions over broad areas came into vogue. Printing of maps by agencies and commercial enterprises began in the early 1800 s. One 


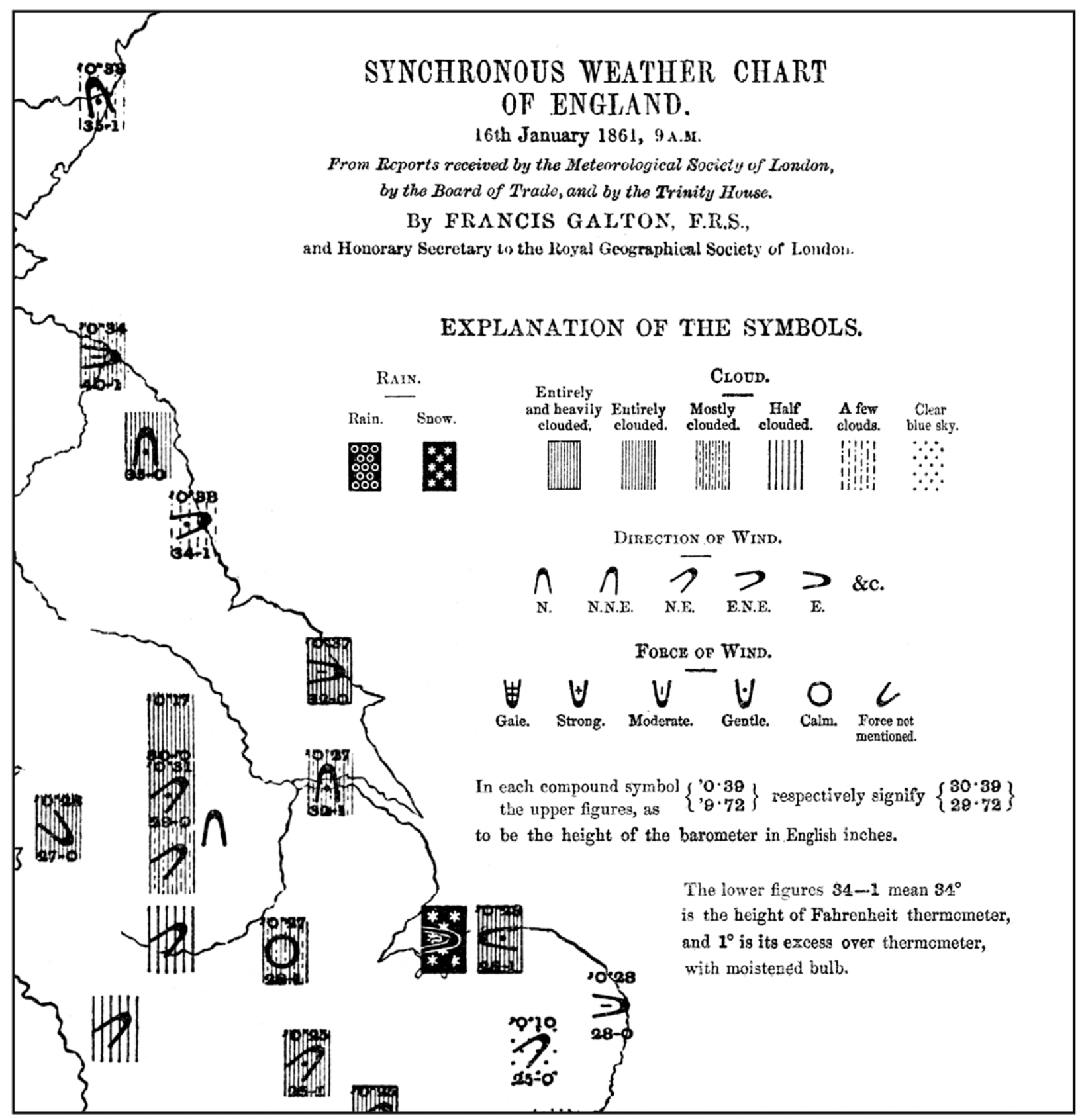

FIG. I7. Weather map showing conditions over England at 0900 LT I6 Jan I86I. The map was published by Francis Galton, FRS, and reproduced in a book by his colleague on the Meteorological Council of Great Britain, Sir Napier Shaw (Shaw 1926).

of the novelties of modern technology produced for Prince Albert's Great Exhibition in London in 1851 was a same-day weather map (Monmonier 1999). But the ways in which weather conditions such as precipitation were represented varied from one mapmaker to the next. In the 1830s, weather maps published by the Franklin Institute in the United States wrote out the weather conditions in full in English at each station (Fig. 16, from Espy 1838), producing a map, which, though beautifully printed, was not readily legible at broad glance. Symbols made for a more comprehensible map. In the 1860s Francis Galton (1822-1911) of the Royal Geographical Society published "synchronous weather charts" of meteorological conditions over England. Galton's maps included iconic graphic symbols for rain or snow at a station. Rain was indicated by a field of circles and snow by a field of asterisks (Fig. 17). These choices may have been influenced by Lambert's suggested symbols of nearly a century earlier (Fig. 15). In this same time period, 


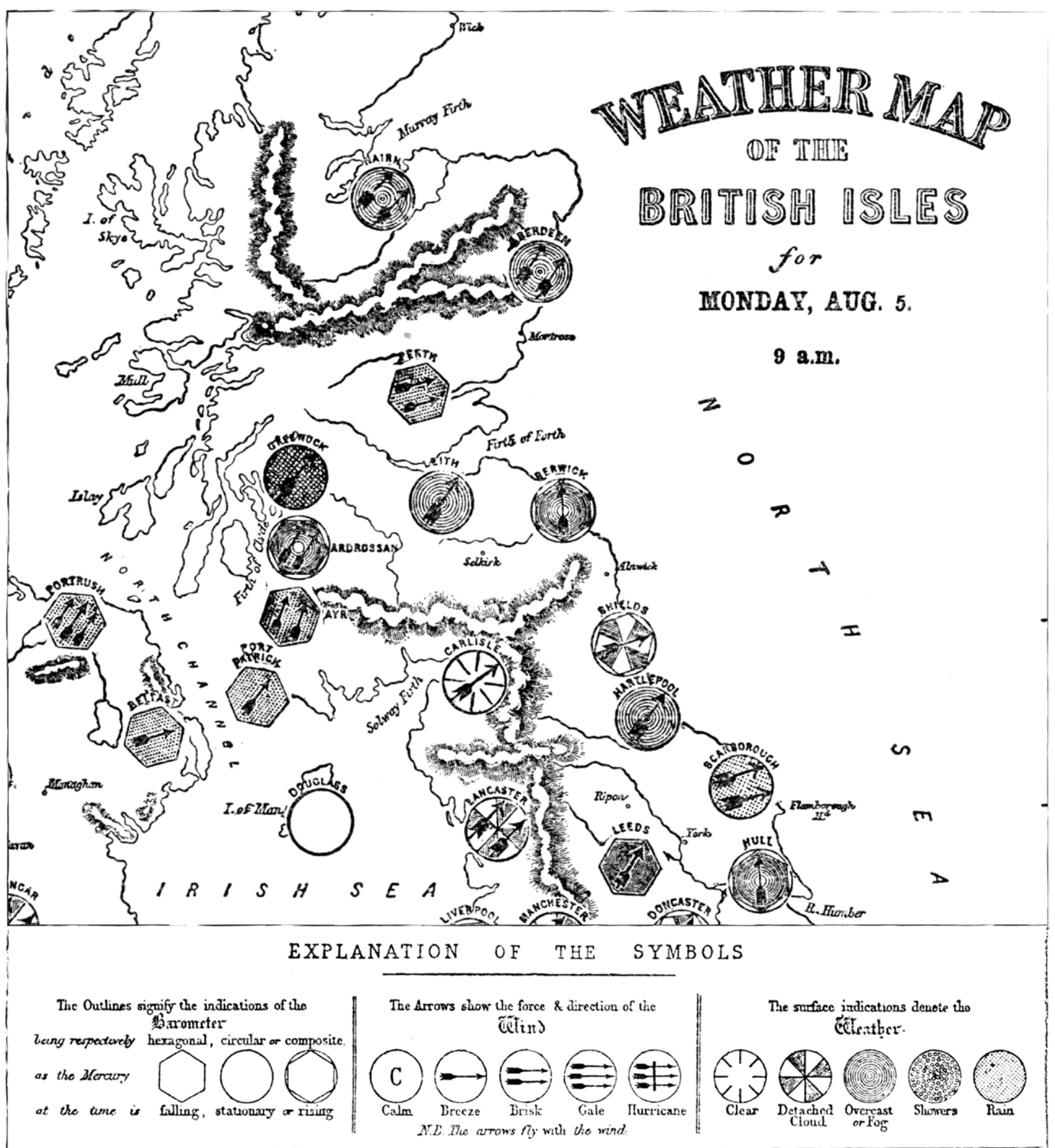

FIG. 18. Weather map of the British Isles issued by the Daily Weather Map Co. for a date in the I860s (year unspecified). Reprinted by Shaw (1926).

a commercially produced British daily weather map used a field of little circles to indicate "showers" and a field of small dots to indicate rain, thus marking a first attempt to distinguish short bursts of rain from steady precipitation, as is still done today (Fig. 18).

Weather mapping was seen as something new and powerful, but it was proceeding in the absence of any international coordination or standard. And with the availability of weather reports by telegraph, weather mapping was taking place in many countries and institutions. ${ }^{2}$ In the mid- to late 1800 s, each country used the explosion of current weather information available by telegraphy according to its own linguistic and cultural traditions, and diverse notation systems

\footnotetext{
${ }^{2}$ For a detailed account of the development of a telegraphic weather-reporting network in the United States, see chapter 7 of Fleming (1990).
} 


\begin{tabular}{|c|c|c|c|c|c|c|c|c|c|c|c|}
\hline & 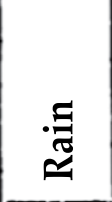 & 莡 & 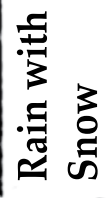 & 常 & 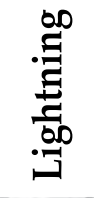 & 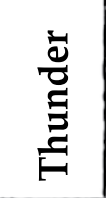 & : & 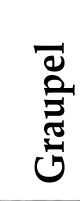 & $\begin{array}{l}0.0 \\
0 \\
1\end{array}$ & $\underset{\Xi}{\stackrel{\Xi}{\Xi}}$ & อั \\
\hline Prussia and Saxony & $\boldsymbol{R}$ & Sch & R,Sch & $\boldsymbol{G}$ & $B l$ & $\boldsymbol{D}$ & $\boldsymbol{H}$ & $G r$ & $\boldsymbol{N}$ & $R f$ & $T h$ \\
\hline Baden & $\boldsymbol{R}$ & $S$ & - & - & - & - & 一 & 一 & - & $R f$ & - \\
\hline Bavaria & $\boldsymbol{H}$ & $S$ & - & $\cdot$ & - & 一 & - & - & $\boldsymbol{N}$ & $R f$ & - \\
\hline Würtemberg & $l i g, r g$ & $\begin{array}{l}\text { Schn, } \\
\text { schn }\end{array}$ & - & Giw & - & - & $\begin{array}{l}H g l, \\
h g l\end{array}$ & Gip & $N b, n b$ & $R f$ & $T h, t h$ \\
\hline Austria & 11 & * & - & t & $\uparrow$ & 一 & $\Delta$ & 一 & $\bullet$ & 一 & 一 \\
\hline Switzerland & $\boldsymbol{R}$ & $\boldsymbol{S}$ & - & $\boldsymbol{G}$ & - & - & $\boldsymbol{H}$ & $\boldsymbol{G r}$ & $N$ & $R f$ & $T h$ \\
\hline France & $\bullet$ & * & - & - & - & - & $\square$ & $\square$ & 0 &.$\Delta$ & $\therefore$ \\
\hline Italy & $p l$ & $\boldsymbol{n v}$ & - & 一 & $l$ & $t$ & $g r$ & 一 & n6 & $b r$ & $r g$ \\
\hline Netherlands & $\boldsymbol{R}, \boldsymbol{r}$ & $S n, 8 n$ & 一 & - & $\begin{array}{l}\text { Фmlt } \\
\text { (1) }\end{array}$ & Donner & Ha, ha & 一 & (2) & 一 & 一 \\
\hline England & $r, r, r$ & $\delta, \underline{\varepsilon}, \underline{8}$ & - & - & $l$ & $\ell$ & $\boldsymbol{h}$ & 一 & $m$ & - & $\boldsymbol{\omega}$ \\
\hline Denmark \& Sweden & $\boldsymbol{H}, \boldsymbol{r}$ & $S, 8$ & Sl & - & $\boldsymbol{Z}$ & $T d$ & $H, h$ & 一 & $T, t$ & 一 & - \\
\hline Russia before 1870 & pl & $N g$ & 一 & - & $\boldsymbol{E}$ & $\boldsymbol{T}$ & $g r$ & 一 & $B r$ & $g b l$ & - \\
\hline Russia after 1870 & 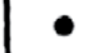 & & e* & $T 3$ & 3 & T & & $\square$ & ○ & & 8 \\
\hline North America & () & (3) & - & 一 & 一 & - & 一 & - & 一 & 一 & 一 \\
\hline
\end{tabular}

FIG. 19. Symbols and letters used in different countries to represent weather conditions at a station on a map as shown in a table in the report of the First International Meteorology Congress in Vienna in 1873.

proliferated and differed from one geographical, cultural, and linguistic context to another, making for inefficiency in the advance of meteorology. As a result, a major concern taken up by the International Meteorological Conference in Vienna in 1873 was to standardize weather mapping among different countries. ${ }^{3}$ Sometimes standardization of procedures can be as important as discovery in science. Standardization may in fact set the stage for the next discovery, by getting everyone to speak the same language! The conference recognized that weather stations in different countries were often indicating weather observations on maps with alphabetic letters

\footnotetext{
${ }^{3}$ Bericht über die Verhandlungen des Internationalen Meteorologen-Congresses zu Wien. 2-16 September 1873. Protokolle und Beilagen (Report on the negotiations of the International Meteorologists Congress in Vienna. 2-16 September 1873. Protocols and supplements). Druck der k. k. Hof- und Staatsdruckerei, 1873 (http://hdl.handle.net/2027 /pst.000007213502).
}

Symbols suggested by the 1873 Congress:

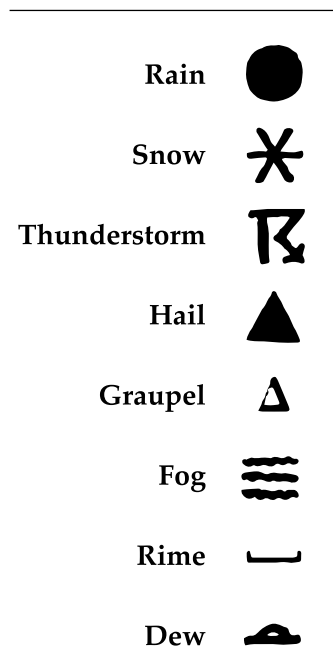

FIG. 20. Weather symbols put forth by the First International Meteorology Congress in Vienna in 1873 for common usage across Europe and North America. See text. 


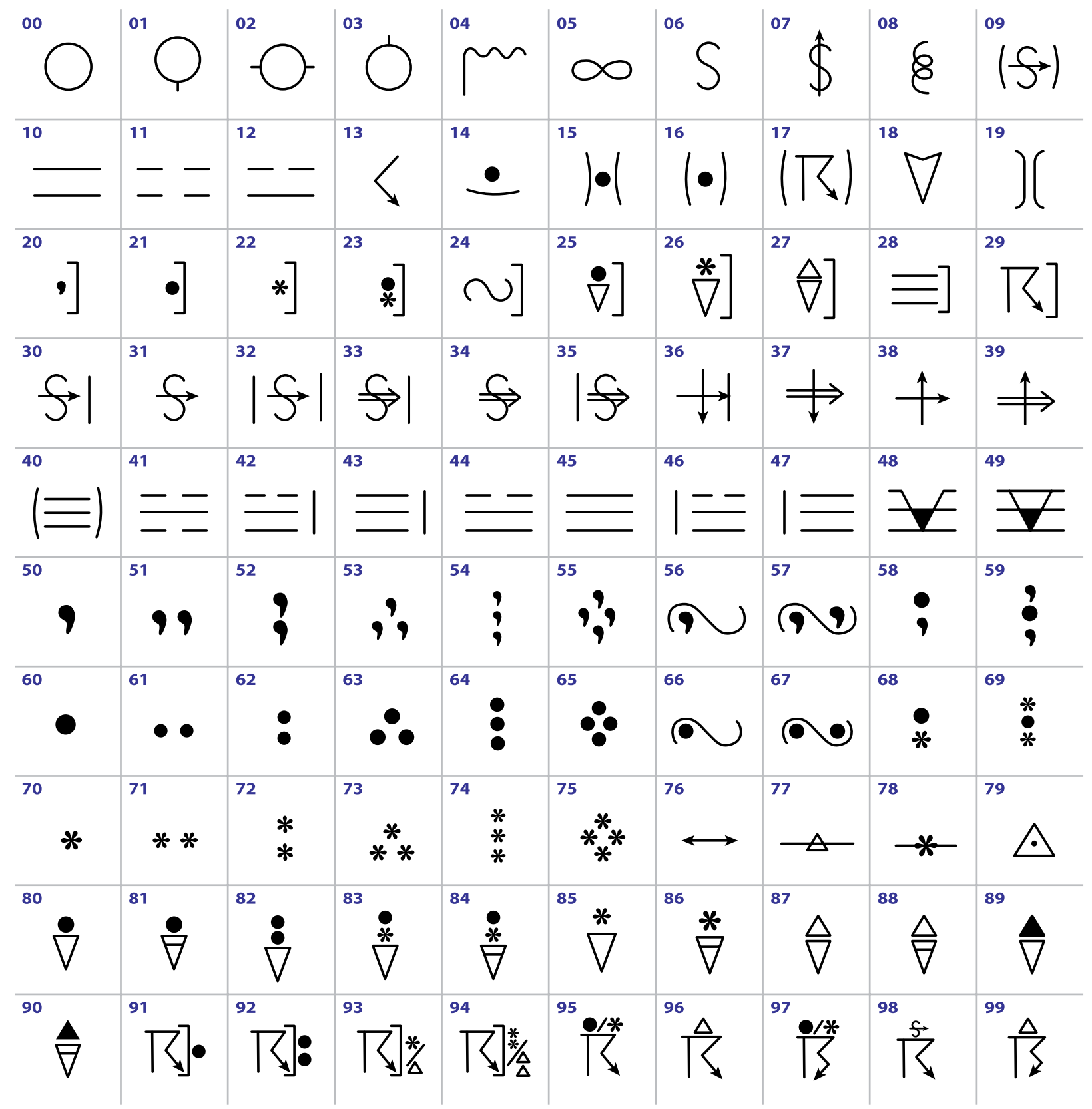

FIG. 21. The 100 weather symbols and codes in the WMO “Manual of codes." These symbols and codes have been in use unaltered for most of the twentieth century and all of the twenty-first century to date (WMO 20I7). The explanations for the symbols are in Fig. ESI.

corresponding to words in their own languages (Fig. 19). For example, a common practice was the use of the single letter R (or a variation, $r, \mathrm{Rg}$, or $®$ ) to indicate rain. That practice worked for Germany, Switzerland, the Netherlands, England, Denmark, Sweden, and North America, where the word for rain began with $r$ in various languages (e.g., regnet, regn, regen). However, in Italy and Russia, the letters $\mathrm{pl}$ (from the Latin "pluviam") were used. Some countries were also beginning to use symbols to indicate weather, but without international coordination.
Weather stations in Austria used a double vertical line to denote rain, while in France and Russia rain was sometimes signified by a solid black dot. In Austria a black dot indicated fog rather than rain.

At the 1873 Vienna meeting, almost exactly a century after Lambert's suggestion of basic weather symbols, the nascent International Meteorological Organization agreed that pictorial or abstract symbols, not alphabetic characters, would be used, and a standard set was adopted and published in the meeting report: a black dot for rain, a snowflake-shaped 


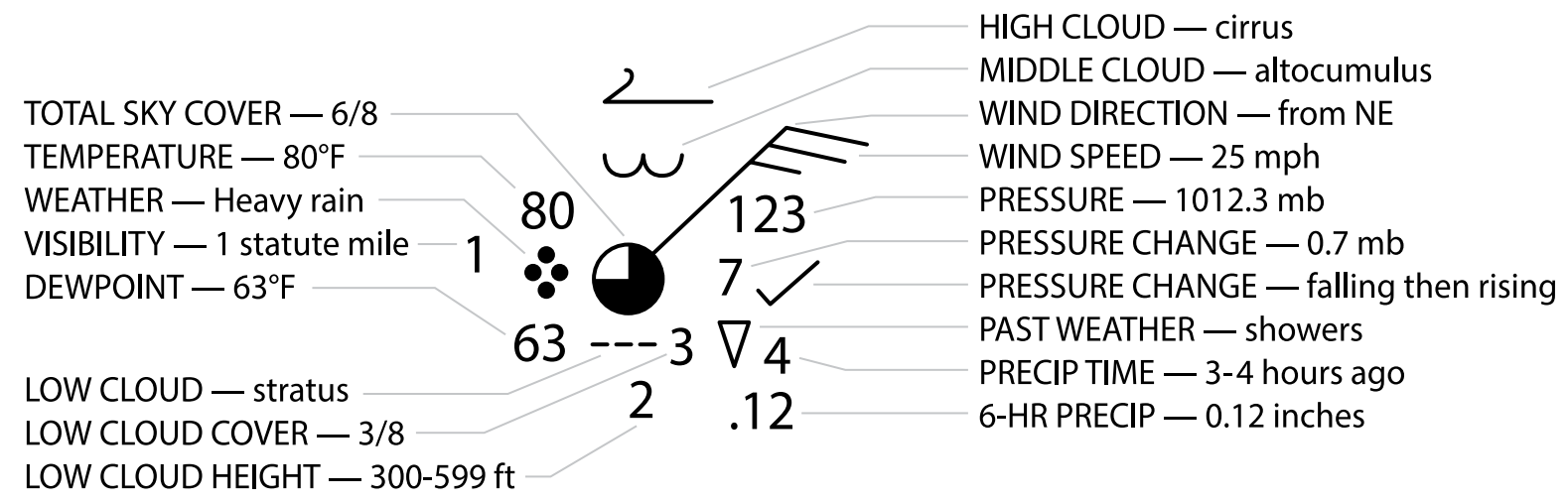

FIG. 22. Instructions for plotting surface weather observations at a station on a map, according to the WMO "Manual of codes" (WMO 2017).

asterisk (better than an $\mathrm{x}$ ) for snow, a dynamic angled line with an arrow tip for thunderstorm, a solid black triangle for hail, an open triangle for soft snow pellets/ freezing rain/sleet, three horizontal bars for fog, a horizontal bracket for rime ice, and a rounded drop upon a horizontal bar for dew (Fig. 20). Again, the symbols are largely abstract. The hail and graupel depart slightly from more typical orthographic symbols but triangles are often used in printing for data points. The symbol for dew combines the dash used for fog and the dot used for rain. The thunderstorm symbol can be reproduced in graphs with a stylized letter $\mathrm{R}$, used not as a letter of the alphabet, but rather as a simple representation of a storm with a lightning bolt. The meeting report contains the additional statement, "the Commission recommends that if any other abbreviations or symbols are used in a publication, their explanation shall be given in a prominent place and not only in the national language, but in several languages." This concern over language and the move away from language toward symbols is not surprising as France, Austria, and Russia were each sprawling empires that encompassed many language groups. It is understandable that meteorologists there would have chosen nonalphabetic symbols to convey basic weather information from diverse locations. A modern analogy is the need for purely pictorial, extremely simple drawings for international road signs-quick comprehension without resort to language to promote smooth movement from country to country.

The symbols adopted in 1873 have evolved through usage and subsequent international agreements into a set of 100 now-standard symbols that are included in the WMO's "Manual on codes" (WMO 2017) and reproduced here in Fig. 21 (See Fig. ES1 in the online supplemental material for explanations of the symbols; https://doi.org//0.1 I75 /BAMS-D-19-007I.2). Along the way many other symbols were suggested (Jelinek 1905; Talman 1916). However, in the end, the weather symbols have retained their characteristic of being heavily influenced by writing, making them fundamentally different from the more artistically inspired cloud symbols. To reach 100 symbols, various nonalphanumeric elements of writing were used in constructing symbols. In addition to periods, commas, and dashes, the tildes $(\sim)$ are now used for freezing rain and drizzle. Brackets and parentheses are used extensively in the symbols. The alphabetic letter $S$ is used several times, and a few mathematical symbols appear, such as the infinity mark $(\infty)$ and some small arrows. Only a few characters are used that do not have their origins in writing (e.g., smoke and tornado are little drawings).

The weather symbols in Fig. 21 as well as the cloud symbols in Fig. 14 are applied to a map by first locating the station, usually indicated by a circle. The symbols are plotted according to a now-standard model (Fig. 22). The weather symbols are placed on the middle left, just below the reported temperature, and the cloud symbols are plotted below and above the station circle. Although the symbols in Figs. 14 and 21 and the plotting method in Fig. 22 still reside in the "Manual on codes," they are not used much in today's operational meteorology, although they can still be seen on current weather maps on certain websites (e.g., http://weather.rap.ucar.edu/surface/).

\section{TWENTIETH CENTURY MAP PLOTTING} IN THE NORWEGIAN SCHOOL AND THE U.S. WEATHER BUREAU. The modern weather and cloud symbols and station model came into common usage sometime in the $1920 \mathrm{~s}$, at the time that the Bergen School, led by Vilhelm Bjerknes (1862-1951), was developing the polar front theory of midlatitude cyclones. At this time, analysts begin to add fronts 


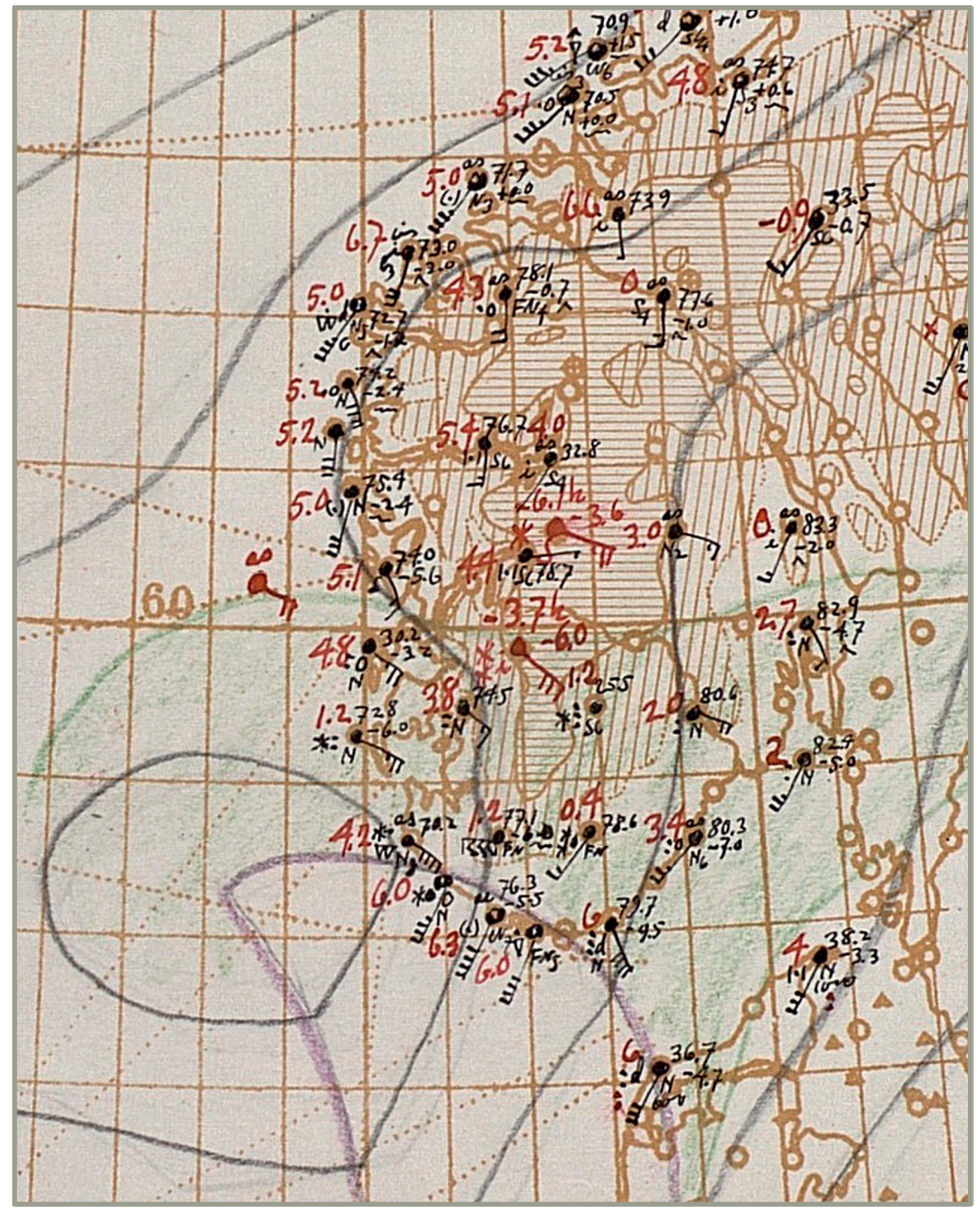

FIG. 23. Norwegian Weather Service surface weather map for I400 LT 28 Jan 1927. 


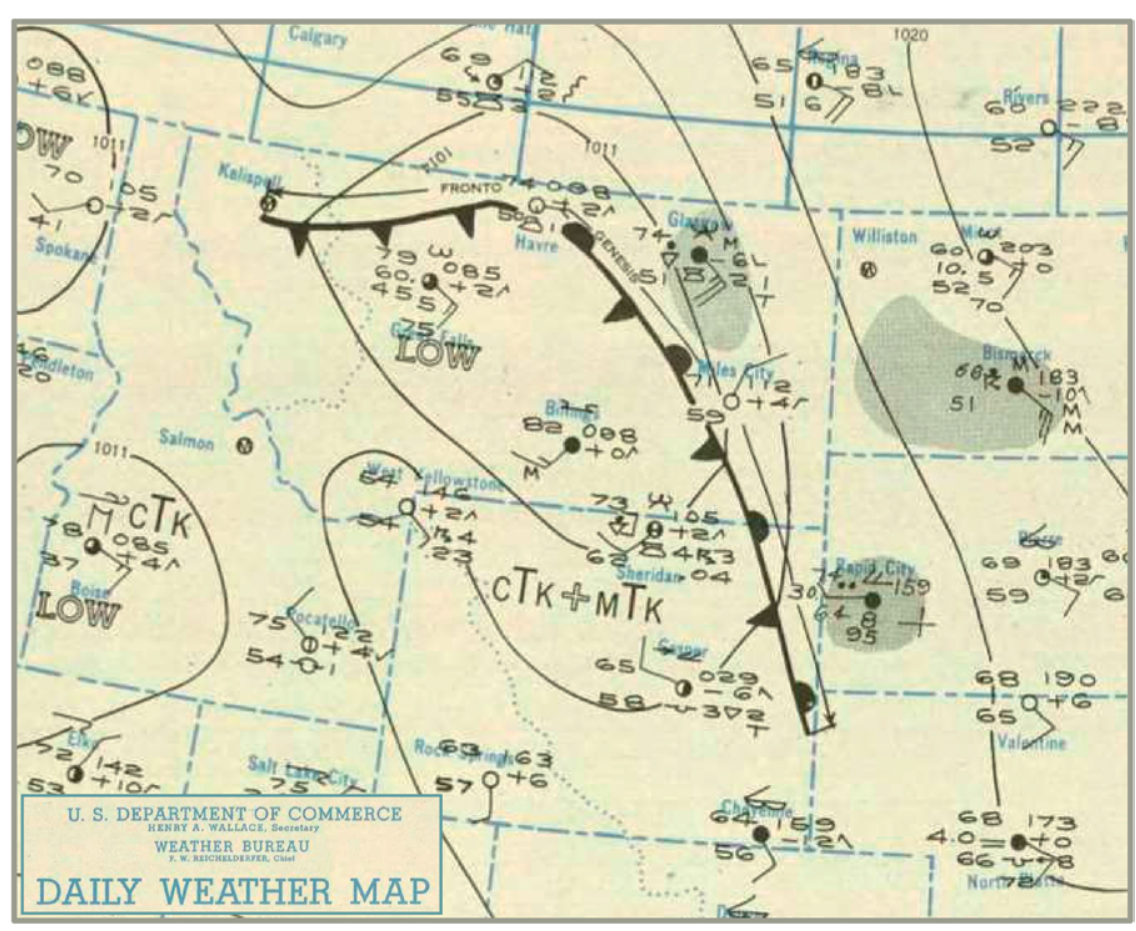

FIG. 24. U.S. Weather Bureau daily weather map for 3 Aug 1945. way as was being done at individual weather stations around the country and world. An example of the Daily Weather Map, from 3 August 1945, is in Fig. 24. This map was plotted by hand, probably by a skilled draftsperson. Notice how the same numeral differs just slightly from one station to the next, and how the symbols for clouds and weather seem to burst with personality, just as handwriting reveals the unique individuality of each writer. These 1927 and 1945 weather maps represent the era when plotting station data by hand added a human touch to weather maps. on top of the weather maps provided by plotters. An example is the map in Fig. 23 used by the Norwegian Weather Service in 1927 to warn of a dangerous storm approaching the Norwegian coast. A frontal cyclone is in the southwest part of the map. Unfortunately, poor ship-to-shore communication prevented the warning from getting to ships and boats offshore, and a disaster ensued, leading Jacob Bjerknes (1897-1975) (Vilhelm's son, then in charge of weather prediction in western Norway) to call for improved communication so that timely warnings could be received at sea. On the map in Fig. 23 are weather symbols for rain, rain showers, snow, snow showers, mixed rain and snow, and a thunderstorm. The combination of strong winds along and ahead of the warm front (northeast of the low center) combined with these wild weather conditions were clearly dangerous for the boats offshore of this highly maritime country. The map itself, with its symbols neatly plotted by hand, not only had the practical ability to tell the story of an oncoming storm, but it did so with visual elegance.

This elegance of weather mapping continued as long as maps were plotted and analyzed by hand. In addition to routine weather mapping in forecast offices, the National Weather Service (formerly U.S. Weather Bureau) for many years published one hand-generated map every day that could be obtained through the mail by subscription. This Daily Weather Map was plotted and analyzed in the same
WHY ARE CLOUD AND WEATHER SYMBOLS DISAPPEARING, AND WHAT ARE THE CONSEQUENCES? The era of hand-plotted weather maps began to decline in the mid-1960s, as meteorology was becoming more technological and complex. The delightful, artistic and clever symbols for the clouds seen from Earth's surface discussed above and celebrated on the AMS ties, scarves, and umbrellas have now fallen into disuse. They have not been printed on the Daily Weather Map since the year 2000. One motivation might be that satellites have been providing global cloud images for the last half century. However, the cloud symbols document a fundamentally different and no less important perspective-how the sky looks from below, which is how people experience clouds from the ground and how pilots experience them in the air as their planes land and take off. This human perspective is hard to quantify or measure by any existing instrument. Another factor is the automation of weather stations, which eliminate the human observer, trained to report the state of the sky and the nature of the current weather. Automation can indicate a few aspects of weather-for example, whether or not it is raining-but not the more subtle aspects indicated in the 100 standardized weather symbols in Fig. 21 or the 27 types of clouds defined in Fig. 14. Thus, neither the nature of the state of the sky nor the more subtle and qualitative aspects 
of weather experienced at the ground are being plotted on maps. Instruments such as vertically pointing cloud radars could partially replace the human-based evaluation of the state of the sky, but as of now there is no systematic network of such observations in place anywhere in the world.

Advances in models, satellite data, physical understanding, and measurement techniques have led to great successes in weather forecasting, warnings of extreme events, and climate assessment over the last century. But along with this march of technology weather maps may have lost some ability to convey the everyday human experience of weather. The disappearance of the qualitative observations represented by symbols at individual weather stations has made it more difficult to assess from a map how the clouds and weather are affecting people looking out the window and up at the sky.

An often-forgotten but important application of weather mapping is how it aids historians, social science researchers, and even fiction writers, who are crucial to the recording of life on Earth. These scholars and artists depend on library resources to carry out their work looking into past events. For example, one might want to know what the weather was like in the United States on the day of the assassination of John F. Kennedy, the attack on the World Trade Center, the launch of the first Apollo moon landing, or some less notable but significant event (e.g., RAH's birthdate; Fig. 24). A quick look at an archived document like the bygone hand-plotted Daily Weather Map efficiently and simply conveyed that information in terms not only of temperature, wind, humidity, and pressure, but also in what kinds of clouds and weather formed the background scene of the event as experienced by people on the ground. Satellite or radar imagery does not convey this human experience of weather, which is so important to artists and writers. Meteorology is an important part of the human experience, and losing the art of weather map plotting has implications that affect our ongoing understanding of the human condition. Dropping the cloud symbols from the Daily Weather Map has removed useful information about the sky overhead. Fortunately, the weather symbols have been retained and access to the Daily Weather Map is available online (www.wpc.ncep.noaa.gov/dailywxmap/index.html). This access is important for maintaining the ability to understand, record, and appreciate the experience of the natural world.

CONCLUSIONS. The cloud and weather symbols used in the age of handcrafted weather map plotting are interesting in their curiously different histories: the convergence of naturalist art and scientific inquiry that led to symbols for clouds overhead, and the use of abstract written symbols to represent weather on the ground. Despite these very different evolutions, these symbols have proven themselves as a way to depict the human experience of the surrounding atmosphere. The wonderment of J. H. Lambert and Luke Howard, and the determined efforts of the early cloud enthusiasts Ley, Hildebrandsson, and Abercromby laid the groundwork for international coding and mapping of clouds and weather by the IMO and WMO. Over the course of more than two centuries, these desires and efforts led to the 27 clever symbols representing different and physically distinct cloud types and the 100 types of weather events as seen by a human observer. However, the implementation and use of these symbols that evolved in the first two-thirds of the twentieth century, when weather mapping was done by hand, have fallen away with increased automation and the disappearance of cloud symbols from the Daily Weather Map. Whether the use of cloud and weather symbols on surface weather maps can or should be revitalized in our hypertechnological age is unclear, though we think it would be beneficial to restore the human element that these symbols represent. In any case, the peculiar and interesting history of how the somewhat enigmatic symbols came about and were used in the age of manual weather plotting seem worth remembering in this centennial year, and the AMS ties, scarves, and umbrellas remain a link to this rich history.

ACKNOWLEDGMENTS. We thank the following individuals and organizations for help in making this article possible: Catherine Ross of the Met Office Library Archives for making the Abercromby photos available; Brianna Cregle of the Rare Books and Special Collections, Firestone Library, Princeton University, for providing an images of the Espy Map; Noel Keenlyside and Jan Asle Olseth of the Geophysical Institute, University of Bergen and the Norwegian Meteorological Institute for providing vintage weather maps from the Bjerknes era; the University of Washington Interlibrary Loan for obtaining copies of the cloud atlases of the 1890s; and Beth Tully for refining the graphics and editing the text.

\section{REFERENCES}

Abercromby, R., 1887: Suggestions for an international nomenclature of clouds. Quart. J. Roy. Meteor. Soc., 13, 154-166, https://doi.org/10.1002/qj.4970136212. 
Anderson, K., 2006: Mapping meteorology. Intimate Universality: Local and Global Themes in the History of Climate and Weather, Science History Publications, 69-92.

Edwards, P. N., 2010: A Vast Machine: Climate Models, Climate Data, and the Politics of Global Warming. MIT Press, $518 \mathrm{pp}$.

Espy, J. P., 1838: Report of the Committee on Meteorology. J. Franklin Inst. State Pa. Mech. Regist., 22, 161-175.

Fleming, J. R., 1990: Meteorology in America, 1800-1870. Johns Hopkins University Press, 264 pp.

— , 2016: Inventing Atmospheric Science: Bjerknes, Rossby, Wexler, and the Foundations of Modern Meteorology. MIT Press, $296 \mathrm{pp}$.

Hildebrandsson, H. H., 1887: Remarks concerning the nomenclature of clouds for ordinary use. Quart. J. Roy. Meteor. Soc., 13, 148-154, https://doi .org/10.1002/qj.4970136211.

— W. Köppen, and G. Neumayer, 1890: Wolken-Atlas (Cloud Atlas). Gustav W. Seitz, 12 pp., plus plates.

—, A. Riggenbach, L. Teisserenc de Bort, 1896: International Cloud Atlas. Gauthier-Villars et Fils, 31 pp., plus 14 sheets of colored maps.

Houze, R. A., Jr., 2014: Cloud Dynamics. 2nd ed. Elsevier, $432 \mathrm{pp}$.

Howard, L., 1803: On the modifications of clouds, and on the principles of their production, suspension, and destruction; being the substance of an essay read before the Askesian Society in 1802-3. Philos. Mag., 16, 344-357, https://doi.org/10.1080 /14786440308676358.

Jelinek, C., and Coauthors, 1905: Jelinek's Anleitung Zur Ausführung Meteorologischer Beobachtungen Nebst Einer Sammlung Von Hilfstafeln. Druck der Kaiserlich-Königlichen Hof- und Staatsdruckere, 227 pp.

Lambert, J. H., 1771: Exposé de quelques observations qu'on pouroit faire pour répandre du jour sur la météorologie. Nouv. Mém. Acad. Roy. Sci. B.-L. Berlin, 2, 60-66.

Ley, W. C., 1894: Cloudland: A study on the structure and characters of clouds. Edward Stanford, 208 pp.
Monmonier, M., 1988: Telegraphy, iconography, and the weather map: Cartographic weather reports by the United States Weather Bureau, 1870-1935. Imago Mundi, 40, 15-31, https://doi.org/10.1080 /03085698808592636.

—, 1999: Air Apparent: How Meteorologists Learned to Map, Predict, and Dramatize Weather. University of Chicago Press, 324 pp.

Pouncy, F. J., 2003: A history of cloud codes and symbols. Weather, 58, 69-80, https://doi.org/10.1256 /wea.219.02.

Rees, R., 1982: Constable, Turner, and views of nature in the nineteenth century. Geogr. Rev., 72, 253-269, https://doi.org/10.2307/214526.

Richards, G. W., and C. Abbe, 1898: A form for the record of cloud observations. Mon. Wea. Rev., 26, 456-457, https://doi.org/10.1175/1520-0493(1898)26 [456b:AFFTRO]2.0.CO;2.

Rossow, W. B., and R. A. Schiffer, 1999: Advances in understanding clouds from ISCCP. Bull. Amer. Meteor. Soc., 80, 2261-2287, https://doi.org/10.1175/1520-04 77(1999)080<2261:AIUCFI >2.0.CO;2.

Ruskin, J., 1839: Remarks on the present state of meteorological science. Trans. London Meteor. Soc., 1, 56-59.

Scott, R. H., 1892: Report on the International Meteorological Conference at Munich, August 26th to September 2nd, 1891. Quart. J. Roy. Meteor. Soc., 18, 1-17, https://doi.org/10.1002/qj.4970188101.

Shaw, S. N., 1926: Meteorology in History. Vol. 1, Manual of Meteorology, Cambridge University Press, 386 pp.

Talman, C. F., 1916: Meteorological symbols. Mon. Wea. Rev., 44, 266-274, https://doi.org/10.1175/1520-0493 (1916)44<265:MS>2.0.CO;2.

WMO, 2017: Manual on codes: International codes. Annex II to the WMO technical regulations, Part A-Alphanumeric codes. WMO Rep. 306, Vol. I.1, 480 pp., www.wmo.int/pages/prog/www/WMO Codes/WMO306_vI1/Publications/2017update /WMO306_vI1_2011UP2017_en.pdf. 